\title{
Analysis of gelsolin expression pattern in developing chicken embryo reveals high $G S N$ expression level in tissues of neural crest origin
}

\author{
Antonina Joanna Mazur • Gabriela Morosan-Puopolo • \\ Aleksandra Makowiecka $\cdot$ Maria Malicka-Błaszkiewicz \\ Dorota Nowak · Beate Brand-Saberi
}

Received: 13 May 2014/ Accepted: 16 October 2014/Published online: 29 October 2014

(C) The Author(s) 2014. This article is published with open access at Springerlink.com

\begin{abstract}
Gelsolin is one of the most intensively studied actin-binding proteins. However, in the literature comprehensive studies of $G S N$ expression during development have not been performed yet in all model organisms. In zebrafish, gelsolin is a dorsalizing factor that modulates bone morphogenetic proteins signaling pathways, whereas knockout of the gelsolin coding gene, GSN is not lethal in murine model. To study the role of gelsolin in development of higher vertebrates, it is crucial to estimate $G S N$ expression pattern during development. Here, we examined GSN expression in the developing chicken embryo. We applied numerous methods to track $G S N$ expression in developing embryos at mRNA and protein level. We noted a characteristic GSN expression pattern. Although $G S N$ transcripts were present in several cell types starting from early developmental stages, a relatively high $G S N$ expression was observed in eye, brain vesicles, midbrain, neural tube, heart tube, and splanchnic mesoderm. In older embryos, we observed a high GSN expression in the cranial ganglia and dorsal root ganglia. A detailed analysis of 10-day-old chicken embryos revealed high amounts of gelsolin especially within the head region: in the olfactory and optic systems, meninges, nerves,
\end{abstract}

Electronic supplementary material The online version of this article (doi:10.1007/s00429-014-0923-5) contains supplementary material, which is available to authorized users.

A. J. Mazur $(\bowtie) \cdot$ A. Makowiecka ·

M. Malicka-Błaszkiewicz · D. Nowak

Department of Cell Pathology, Faculty of Biotechnology,

University of Wroclaw, ul. Joliot-Curie 14a, 50-383 Wrocław,

Poland

e-mail: ajmazur@ibmb.uni.wroc.pl

G. Morosan-Puopolo · B. Brand-Saberi

Department of Anatomy and Molecular Embryology, Ruhr

University of Bochum, Bochum, Germany muscles, presumptive pituitary gland, and pericytes, but not oligodendrocytes in the brain. Obtained results suggest that $G S N$ is expressed at high levels in some tissues of ectodermal origin including all neural crest derivatives. Additionally, we describe that silencing of $G S N$ expression in brain vesicles leads to altered morphology of the mesencephalon. This implies gelsolin is crucial for chicken brain development.

Keywords Gelsolin - Chicken development - Nervous system $\cdot$ Neural crest · Optic and olfactory systems · Brain

$\begin{array}{ll}\text { Abbreviations } \\ \text { ABPs } & \text { Actin-binding proteins } \\ \text { CNS } & \text { Central nervous system } \\ \text { Dox } & \text { Doxycycline } \\ \text { E } & \text { Embryonic day } \\ \text { EGFP } & \text { Enhanced fluorescent protein } \\ G d & \text { Gallus domesticus } \\ G S N & \text { Gene coding gelsolin } \\ \text { HH-stage } & \text { Chicken developmental stage according to } \\ & \text { Hamburger and Hamilton } \\ \text { Hs } & \text { Homo Sapiens } \\ \text { NC } & \text { Neural crest } \\ \text { PNS } & \text { Peripheral nervous system } \\ \text { scRNAmir } & \text { microRNA-adapted scrambled RNA } \\ \text { shRNAmir } & \text { microRNA-adapted short hairpin RNA }\end{array}$

\section{Introduction}

Actins, abundantly expressed in all animal cell types, are capable of forming polymers and take part in several cellular processes such as cell motility, chemoattractant- 
controlled (or directed) migration, trafficking of cellular organelles and chromosomes, junction formation, mitosis, transcription, and muscle contraction (Perrin and Ervasti 2010). Consequently, it is understandable that actin dynamics have to be strictly controlled. There are more than 100 Actin-binding proteins (ABPs), which regulate actin polymerization/depolymerization and involvement in several cellular processes (Winder and Ayscough 2005).

Although it was shown that actin is indispensable for mammalian embryonic development (Shawlot et al. 1998), not much is known about the role of ABPs in vertebrate embryo development. There are, however, some exceptions. For instance, it has been shown that thymosin beta4 plays a role in brain development of chicken embryos (Wirsching et al. 2012) and that it is expressed in the neural tube and brain vesicles, the heart, blood vessels, and feathers (Dathe and Brand-Saberi 2004). The presence of thymosin beta4 mRNA was strongly manifested in neural tissues like the neural tube and dorsal root ganglia. These results are similar to those obtained by researchers, who studied thymosin beta4 expression in mouse embryos (Gómez-Márquez et al. 1996). In contrast, another thymosin beta family member, thymosin beta $15^{\text {avian }}$ is asymmetrically expressed in Hensen's node and could thus be involved in left/right axis formation; it has been described to have a function in myogenesis in chicken embryos (Chankiewitz et al. 2014). Other G-actin-binding proteins belong to the ADF/cofilin family. Actin depolymerizing factor (ADF) seems to be dispensable during mouse embryo development (Gurniak et al. 2005), but n-cofilin is crucial for migration of cells derived from the paraxial mesoderm. On the other hand, decreased expression of non-muscle cofilin (n-cofilin) in murine preimplantation embryos is important for compaction during blastocyst formation (Ma et al. 2009).

Here, we focus on the gelsolin expression pattern in developing chicken embryos. Gelsolin is coded by one gene $(G S N)$; however, its expression yields several protein isoforms. In humans, the existence of three isoforms: plasma (isoform a, $86 \mathrm{kDa}$ ), cytoplasmic (isoform b, $81 \mathrm{kDa}$ ), and "brain" (isoform c, $82 \mathrm{kDa}$ ) is well documented. Furthermore, the presence of some other isoforms can be predicted. Gelsolin, a $\mathrm{Ca}^{2+}$, phosphatidylinositol 4,5-biphosphate $\left(\mathrm{PIP}_{2}\right)$ and $\mathrm{pH}$-dependent six-domain (G1G6) protein, severs actin filaments, caps the barbed ends of actin filaments and under certain conditions nucleates actin monomers (Mannherz et al. 2010; Li et al. 2012; Nag et al. 2013). However, gelsolin seems to have more functions than severing actin filaments in the cells or scavenging microfilaments in the body fluids. Gelsolin is also directly involved in nuclear processes such as transcription. It binds to hypoxia-inducible factor 1 (HIF-1), a transcription factor
(Li et al. 2009) and forms complexes with steroid hormones, e.g., androgens (Nishimura et al. 2003) and estrogens (Ambrosino et al. 2010). This process is crucial for entry of hormones bound to their receptor into the nucleus and for forming transcription complexes. Moreover, several reports point toward involvement of gelsolin in various human cancers, due to the observation that GSN expression was downregulated in numerous types of cancers, e.g., breast, bladder, colon, gastric, kidney, lung, oral, ovarian, pancreatic, and prostate cancer (Li et al. 2012). This is corroborated by results published by Tanaka et al. (2006) showing that downregulation of GSN expression by applying siRNA promoted epithelial-mesenchymal transition (EMT) of mammary epithelial cells. It suggests gelsolin is an important tumor suppressor (Li et al. 2012).

Our previous studies focused on the role of gelsolin in cell motility of human tumor cells (Mazur et al. 2010) with special emphasis on colon adenocarcinoma (Litwin et al. 2009, 2012) and melanoma cells (Litwin et al. 2012). Since gelsolin probably plays a significant role in cell transformation into tumor cells, it is likely to have a role during embryonic development, because in both situations cells detach, migrate/invade and colonize new environments. That is why we decided to determine GSN expression pattern in chicken embryo development, since not much is known about the role of gelsolin in vertebrate embryo development. Kwiatkowski's group generated mice with GSN gene knockout, which were subsequently subjected to several studies. They reported that the absence of gelsolin was not lethal and gave relatively mild symptoms including impaired fibroblast motility and inflammatory response (Witke et al. 1995), or that it affected the morphogenesis of mammary ducts (Crowley et al. 2000). It could be explained by taking over of gelsolin functions in $\mathrm{GSN}^{-/-}$ mice by other members of the gelsolin protein family which in higher vertebrates includes CapG, adseverin, flightless I, advillin, villin, villin-like protein, and supervillin (Nag et al. 2013). Interestingly, it was shown that gelsolin is a dorsalizing factor in Danio rerio development. Depleting embryos of GSN mRNA resulted in affected development of head structures and eye and resulted in less pigmented embryos. Kanungo et al. (2003) showed that gelsolin has an important regulatory function as a modulator of bone morphogenetic protein signaling pathways involving chordin which is responsible for the formation of the dorsoventral axis in zebrafish. In this work, we present the first comprehensive study of GSN expression in the chicken embryo, which answers questions at which developmental stages GSN is expressed, what is the pattern of expression and if gelsolin is present at protein level in chicken. Additionally, we show that gelsolin is required for early brain development. 


\section{Materials and methods}

Ethics statement

Regulations concerning the usage of chicken embryos for experimental procedures are described elsewhere (Morosan-Puopolo et al. 2014). The chicken embryos sacrificed for this work were between developmental stages HH8 and HH36 (E 10). No permits were required for this study.

Bioinformatics analysis

Amino acid sequence alignments were performed using MAFFT, the multiple alignment program for amino acid or nucleotide sequences, version 7 (Katoh et al. 2005; Katoh and Standley 2013). Following amino acid sequences were analyzed: human gelsolin isoforms a (NP_000168.1, Pubmed), b (Pubmed: NP_937895.1), c (Pubmed: NP_001121138.1), d (Pubmed: NP_001244958.1), f (Pubmed: NP_001121135.2), and chicken gelsolin (NP_ 990265.1, Pubmed). For other analyses following gene sequence was used: chicken (Gallus domesticus) GSN: 395774 (Pubmed).

\section{Cloning}

Dermis of chicken embryo at stage HH36 (E10) was dissected, followed by rinsing in ice-cold PBS, next homogenized by cutting and frozen at $-80{ }^{\circ} \mathrm{C}$. After tissue thawing total RNA was isolated with the help of NucleoSpin $^{\circledR}$ RNA II Kit (Macherey-Nagel). $1 \mu \mathrm{g}$ of RNA was reverse transcribed using High Capacity cDNA Reverse Transcription Kit (Applied Biosystems) following the manufacturer's instructions. PCR reactions with following primers 5'-CTGGTTAGGAGATGAAAGCTC-3' and 5'CTGGTCCTTGTCCCTCCAGTTC- $3^{\prime}$ for gelsolin were carried out to achieve product, which was subsequently cloned into pDrive plasmid (Qiagen). Primers were designed based on a nucleotide sequence coding for chicken gelsolin found in Pubmed under NM_204934 number. A Pyrococcus furiosus (Pfu) polymerase was used (Fermentas) to avoid introducing any mistakes into nucleotide sequence. The correctness of DNA construct was verified by sequencing.

\section{RNA interference}

The strategy for obtaining plasmids coding for shRNAmirs targeting gelsolin mRNA was based on Tol2 transposonmediated technique (Iguchi et al. 2012). The Tol2-EGFP vector system (Koga et al. 1996; Kawakami et al. 2000; Kawakami 2007; Sato et al. 2007) was kindly provided as a gift from Koichi Kawakami (Division of Molecular and
Developmental Biology, National Institute of Genetics, Mishima, Shizuoka 411-8540, Japan). Following oligonucleotides were ordered: for shRNAmir-Gd_GSN_921, 5' TGCTGTTGACAGTGAGCGCACTGATACAGCCAATA GAAAGTAGTGAAGCCACAGATGTACTTTCTATTGG CTGTATCAGTTTGCCTACTGCCTCGGA-3'; for shRNA mir-Gd_GSN_1137，5'-TGCTGTTGACAGTGAGCGCGC TACTGATTTCATTGATAAGTAGTGAAGCCACA $\overline{\mathrm{GAT}}$ GTACTTATCAATGAAATCA GTAGCTTGCCTACTGC CTCGGA-3'; for shRNAmir-Gd_GSN_1647, 5'-TGCTGT TGACAGTGAGCGACCACCTC-ATCTGATGAGCATGT AGTGAAGCCACAGATGTACATGCTCATCAGATGAG GTGGCTGCCTACTGCCTCGGA-3'; for scRNAmir$\overline{G d \_G S N}$ _921, 5'-TGCTGTTGACA-GTGAGCGCGAATA CGGATAAGCATACACATAGTGAAGCCACA $\overline{\text { GATGTA }}$ TGTGTATGCTTATCCGTATTCTTGCCTACTGCCTCG GA-3'; for scRNAmir-Gd_GSN_1137, 5'-TGCTGTTGAC AGTGAGCGCTTATTAATACCGGTATGACGTTAGTG AAGCCACAG-ATGTAACGTCATACCGGTATTAATA ATTGCCTACTGCCTCGGA-3'; for scRNAmir$\overline{G d}$ GSN_1647, 5'-TGCTGTTGACAGTGAGCGCTTCG CCAGGCGACCATTATGCTAGTGAAGCCACAGATG TAGCATAATGGTCGCCTGGCGAATTGCCTACTGCC TCGGA-3'. The sequences, which are underlined correspond to antisense and sense target sequences based on a nucleotide sequence coding for chicken gelsolin found in Pubmed under NM_204934 number. Primers: 5'-GAT GGCTGCTCGAGAAGGTATATTGCTGTTGAC-AGTG AGCG-3' and 5'-GTCTAGA-GGAATTCCGAGGCAG TAGGCA-3' were used to amplify by PCR mir-based scRNAs and shRNAs. A HotStarTaq ${ }^{\circledR}$ DNA polymerase with provided Q-Solution ${ }^{\circledR}$ was used (Qiagen) to amplify templates with high degree of secondary structures. PCR products were cloned into pT2K-TBI-shRNAmir vector using XhoI and EcoRI sites. The correctness of DNA constructs was verified by sequencing.

In ovo electroporation

Electroporation was performed according to the procedure described elsewhere (Scaal et al. 2004; Dai et al. 2005) using the Intracel TSS20 OVODYNE device. 1-2 $\mu$ of plasmids solution $(2-4 \mu \mathrm{g} / \mu \mathrm{l})$ was electroporated into the brain vesicles of embryos at HH-stages 11-12. The plasmids were mixed in the following ratio: pT2K-CAGGSrtTA-M2 (rtTA-M2 doxycycline-binding element): pT2KTBI-shRNAmirs: pCAGGS-T2TP (Tol2 transposase) $=1: 2: 2$ (Iguchi et al. 2012). After electroporation, the eggs were sealed with tape and reincubated. $12 \mathrm{~h}$ later $500 \mu \mathrm{l}$ of doxycycline (Dox) dissolved in HANKS solution (140 mM NaCl, $5.4 \mathrm{mM} \mathrm{KCl,} 5.6 \mathrm{mM}$ glucose, $0.34 \mathrm{mM}$ $\mathrm{Na}_{2} \mathrm{HPO}_{4}, 10 \mathrm{mM}$ HEPES, $1 \mathrm{mM} \mathrm{CaCl}, \mathrm{pH}$ 7.0) to final concentration of $0.1 \mathrm{mg} / \mathrm{ml}$ was injected between the 
embryo and yolk to trigger the expression of scRNAmirs or shRNAmirs and EGFP (Watanabe et al. 2007). $24 \mathrm{~h}$ later the embryos were in ovo photographed and harvested for following in situ hybridization experiments.

In situ hybridization

Fertilized chicken eggs were incubated at $37{ }^{\circ} \mathrm{C}$ and $72 \%$ humidity and staged according to Hamburger and Hamilton (1992). Whole mount chicken embryos at HH-stages 9-36 were fixed overnight at $4{ }^{\circ} \mathrm{C}$ in $4 \%$ formaldehyde (FA). The detailed protocol is described elsewhere (Nieto et al. 1996). As a template for preparing riboprobes pDrivegelsolin fragment plasmid was used. Two probes were prepared, sense and antisense. Both probes were digoxigenin labeled with DIG RNA Labeling Mix (Roche) according to manufacturer's protocols. Sense probe being a negative control gave no signal. The probe recognizing CECR2 transcript is described elsewhere (Chen et al.). Selected stained embryos were embedded in $3 \%$ agarose and cut with the help of Leica VT 1000S vibratome at $60 \mu \mathrm{m}$, next mounted on glass and finally analyzed using Axioplan 2 microscope (Zeiss) and Axio Vision software (Zeiss).

\section{RT-PCR analysis}

Embryos at different stages and organs dissected from embryos at stage HH36 were stored in RNAlater RNA stabilization reagent (QIAgen) at $-20^{\circ} \mathrm{C}$. Following total RNA was isolated with the help of NucleoSpin ${ }^{\circledR}$ RNA II Kit (Macherey-Nagel). $0.5 \mu \mathrm{g}$ of RNA was reversely transcribed using High Capacity cDNA Reverse Transcription Kit (Applied Biosystems) following the manufacturer's instructions. $1 \mu \mathrm{l}$ of transcribed cDNA was used for the subsequent PCR with primers listed in Table 1, the reaction final volume was $15 \mu \mathrm{l}$, PCRs were carried out under following conditions: initial denaturation $2 \mathrm{~min}$ $95^{\circ} \mathrm{C}, 30$ cycles of denaturation $\left(30 \mathrm{~s}\right.$ at $\left.95^{\circ} \mathrm{C}\right)$, annealing $(30 \mathrm{~s}$ at $\mathrm{Tm})$ and elongation $\left(1 \mathrm{~min}\right.$ at $\left.72{ }^{\circ} \mathrm{C}\right)$. As reference gene served chicken $A C T B$. PCR products were subjected to horizontal DNA electrophoresis in $2 \%$ agarose gel/ $1 \times$ Tris-acetate-EDTA (TAE) buffer, as a molecular mass marker served GeneRuler ${ }^{\mathrm{TM}} 50$ bp DNA ladder (Fermentas). Pictures were taken with ChemiDoc ${ }^{\mathrm{TM}}$ MP System (Bio-Rad) and further analyzed with the help of ImageLab 4.0 software (Bio-Rad).

\section{Isolation of tissue extracts}

For Western blot analysis, whole chicken embryos at HHstages 9-25 and chosen organs from chicken embryos at stage HH36 were lysed on ice with RIPA buffer $(50 \mathrm{mM}$
Tris $\mathrm{HCl} \mathrm{pH}$ 8.0, $150 \mathrm{mM} \mathrm{NaCl}, 1 \% \mathrm{NP}-40,0.5 \%$ sodium deoxycholate, $0.1 \%$ SDS) supplemented with proteases inhibitors cocktail (PIC) (Sigma) diluted at 1:100. Next the lysates were threefold frozen-thawed and centrifuged at $10,000 \times g$ for $10 \mathrm{~min}$ at $4{ }^{\circ} \mathrm{C}$. Supernatants for further analysis were stored at $-80{ }^{\circ} \mathrm{C}$.

\section{Western blot analysis}

Protein concentration in cellular extracts was determined by the standard Bradford procedure (Bradford 1976). Samples of identical protein amount $(30 \mu \mathrm{g})$ were separated by $10 \%$ polyacrylamide gel electrophoresis in the presence of sodium dodecylsulfate (SDS-PAGE) according to Laemmli (1970), as a molecular mass marker served PageRuler ${ }^{\mathrm{TM}}$ Prestained Protein Ladder (Fermentas). This was followed by transfer to nitrocellulose membrane, using the procedure described elsewhere (Towbin et al. 1979). Monoclonal rabbit anti-gelsolin antibodies (Abcam, clone EPR1942) at dilution 1:5,000 were used to visualize gelsolin band on nitrocellulose. $\beta$ actin and $\beta$ tubulin recognized by monoclonal mouse anti- $\beta$ actin (Sigma, clone AC15 ) and anti- $\beta$ tubulin (TUB 2.1) antibodies, were used as reference proteins. Secondary antibodies conjugated to horseradish peroxidase (HRP) were applied according to the manufacturer's protocols (Cell Signaling). Immunoblots were developed using the Western blotting Luminol Reagent (Santa Cruz Biotechnology), photos of blots were taken with ChemiDoc ${ }^{\mathrm{TM}}$ MP System (Bio-Rad) and further analyzed with the help of ImageLab 4.0 software (BioRad).

\section{Immunohistochemistry}

Whole embryos at stage $\mathrm{HH} 33$ and parts of embryos at stage HH36 were collected and fixed in $4 \%$ formaldehyde (FA) for at least $24 \mathrm{~h}$. Next samples were dehydrated and embedded in Paraplast ${ }^{\circledR}$ (Sigma), $7 \mu \mathrm{m}$ thick sections were cut with the help of a rotation microtome (Leitz) and mounted on SuperFrost Plus microscope slides (MenzelGläser). FA-fixed and paraffin-embedded sections of chicken embryos were deparaffinized in xylene and subsequently rehydrated by standard procedure. Antigen retrieval was performed by boiling slides in citrate buffer (10 mM Na-citrate pH 6.0, $0.05 \%$ Tween 20) for $20 \mathrm{~min}$. Endogenous peroxidase activity was blocked according to EnVision $^{\mathrm{TM}}$ System-HRP (AEC) ${ }^{+}$kit manufacturer's protocol (DAKO). Sections were blocked for $1 \mathrm{~h}$ with $3 \%$ goat serum in $1 \%$ bovine serum albumin (BSA) in $50 \mathrm{mM}$ Tris $\mathrm{pH}$ 7.6. Following the slides were incubated overnight at $4{ }^{\circ} \mathrm{C}$ with primary rabbit anti-gelsolin antibodies (Abcam, clone EPR1942) diluted at 1:500. As a negative control normal rabbit antibodies were used. DAKO 
Table 1 Nucleotide sequences, amplicon sizes, and annealing temperatures $(\mathrm{Tm})$ of primers used in RT-PCR analysis

\begin{tabular}{llll}
\hline Primer & Sequence & Amplicon size $(\mathrm{nt})$ & Tm $\left({ }^{\circ} \mathrm{C}\right)$ \\
\hline$G d \_A C T B \_f$ & $5^{\prime}$-CAGAAGGAGATCACAGCCCTG-3' & 221 & 63 \\
$G d \_A C T B \_r$ & $5^{\prime}$-CCAACACCCACACCCCTGTG-3' & & \\
$G d \_G S N \_f$ & $5^{\prime}$-GCCATGAATCCTCAACGTTC-3' & 215 & 63 \\
$G d \_G S N \_r$ & $5^{\prime}$-CATCCTTGACCTTGGCAGT-3' & & \\
\hline
\end{tabular}

EnVision $^{\mathrm{TM}}$ System-HRP $(\mathrm{AEC})^{+}$kit was used to visualize the sites recognized by primary antibodies. The reaction was developed with 3-amino-9 ethylocarbazol (AEC) for $10 \mathrm{~min}$. Next, the sections were counterstained with Mayer's hematoxylin solution (Sigma) for $10 \mathrm{~min}$ to visualize cell nuclei. Photos at lower magnifications were taken using Olympus SZ61 stereo microscope and photos at higher magnification were taken using Olympus FV500 microscope.

\section{Results}

The chicken gelsolin sequence

According to information about the chicken gelsolin gene (GSN, gene id: 395774, Pubmed), there is only one transcript of this gene coding for chicken gelsolin, of which the amino acid sequence is $77 \%$ identical to the human gelsolin isoform a-known as plasma gelsolin (Online Resource 1, Fig. S1A). The human isoform b of gelsolin, called cytoplasmic gelsolin ubiquitously present in numerous cell types is a shorter protein in comparison to human plasma gelsolin. In Online Resource 1, Fig. S1A, the first amino acids of both plasma and cytoplasmic gelsolins are marked. Major differences between chicken and human gelsolin are localized in the N-terminus of the compared amino acid sequences. Because in Homo sapiens, there is also the gelsolin isoform c found in oligodendrocytes of the central nervous system (CNS) (Vouyiouklis and Brophy 1997) and possibly other isoforms are also present (Nag et al. 2013), we additionally compared the N-terminus of chicken gelsolin with the N-termini of human gelsolin isoforms c, d, and $\mathrm{f}$ (Fig. 1a). Isoforms of human gelsolins differ only within their $\mathrm{N}$-termini. The bioinformatical analysis revealed that the $\mathrm{N}$-terminus of chicken gelsolin is not explicitly similar to any human gelsolin isoform. We have prepared a plasmid coding for two probes, sense and antisense, which hybridize to the GSN transcript (Fig. 1b). After cloning of cDNA fragment coding part of chicken gelsolin into pDrive plasmid the DNA construct was sequenced to check the correctness of cloning. It came out there were two discrepancies in positions 743 and 786 (counting from ATG codon of plasma gelsolin) of nucleotide sequence comparing to nucleotide sequence found in Pubmed under NP_990265.1 number. Because of that we decided to clone the whole cDNA coding for gelsolin and sequence it. For this purpose, we took Phusion $^{\mathrm{TM}}$ polymerase, which ensures high-fidelity amplification. It came out there were some differences between sequenced DNA and nucleotide sequence (NM_204934) found in Pubmed. Most of them do not result in changed amino acids. However, four amino acids are different (Online Resource 1, Fig. S1A). Instead of isoleucine in position 13 there is valine, in position 98, there is lysine instead of arginine. In position 248, there is arginine and not lysine, and in position 661, there is histidine instead of tyrosine. Interestingly, in corresponding to 248 and 661 positions in human gelsolin, there are arginine (position 252) and histidine (position 665), respectively. Differing amino acids are located in signal peptide $\left(\mathrm{Val}^{13}\right)$, domain G1 ( $\mathrm{Lys}^{98}$ ), domain G2 ( $\mathrm{Arg}^{248}$ ), and in the linker region between domains G5 and G6 (His ${ }^{661}$ ) (Online Resource 1, Fig. S1B). Any of these residues plays a special role in functioning of gelsolin (Online Resource 1, Fig. S1B) (Choe et al. 2002; Nag et al. 2009). The nucleotide sequence found in Pubmed under the number: NM_204934 was derived from sequence published under following number: AF042795.1 and has not been yet verified by NCBI, what could explain the differences between this sequence and sequence coming from our analysis.

Whole mount in situ hybridization experiments

Having the antisense probe in hands recognizing the GSN transcript, we subsequently performed in situ hybridization experiments. In chicken embryos at $\mathrm{HH}$-stage 8, we could observe relatively weak and homogenous GSN expression found mainly in the head fold and the caudal segmental plate (Fig. 2a). In embryos at $\mathrm{HH}$-stages 10-11, a stronger $G S N$ expression was observed in the eye vesicle, brain vesicles, the midbrain, the heart tube, the splanchnopleure, and the neural tube (Fig. 2b-d). We could not detect any $G S N$ expression in the somites. In chicken embryos at $\mathrm{HH}-$ stage 18 (Fig. 2e-j), we observed distinct expression of $G S N$ in cranial and dorsal root ganglia, in the atrioventricular canal, head mesenchyme, the eye cup, and in dermal cells underlying the epidermal ectoderm. Moreover, strong presence of GSN transcript was observed in mesenchymal cells surrounding the aorta (Fig. $\left.2 h^{\prime}\right)$ and in the 


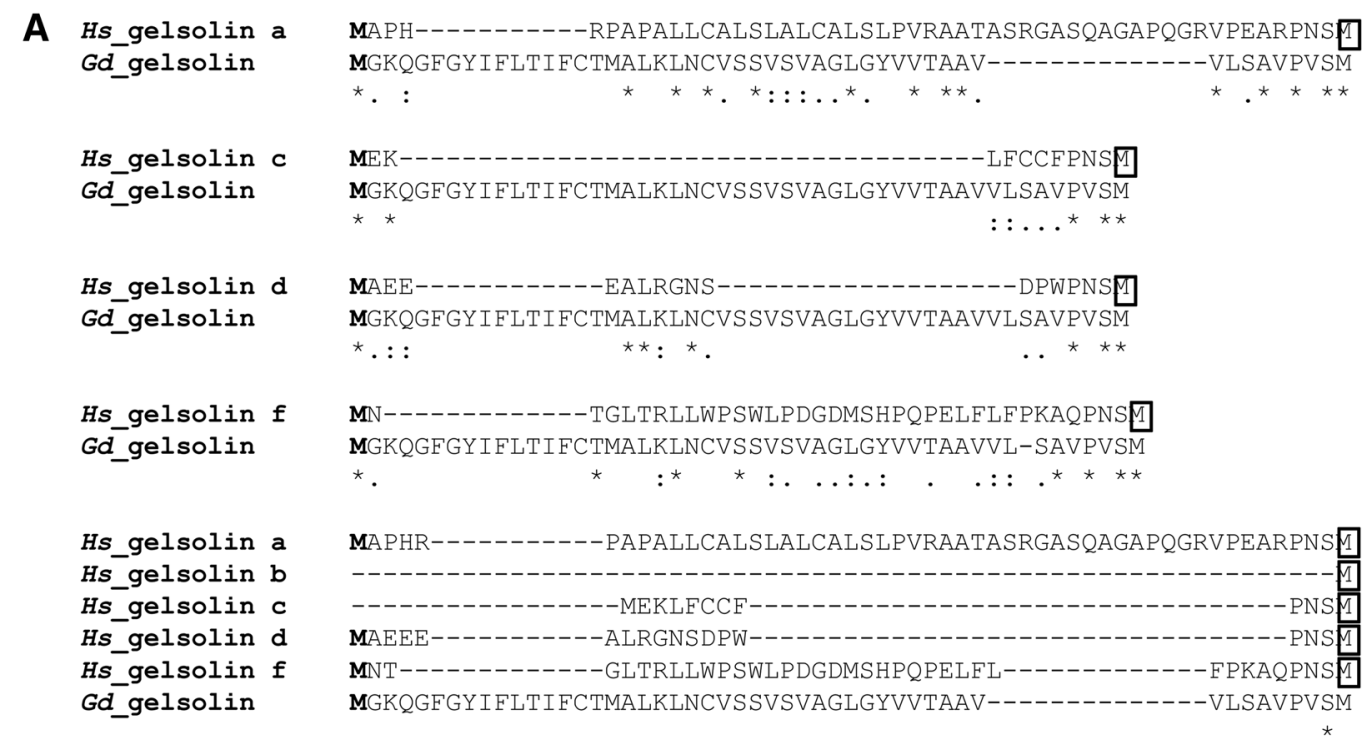

M - begining of gelsolin

M- begining of gelsolin isoform b (Homo sapiens)

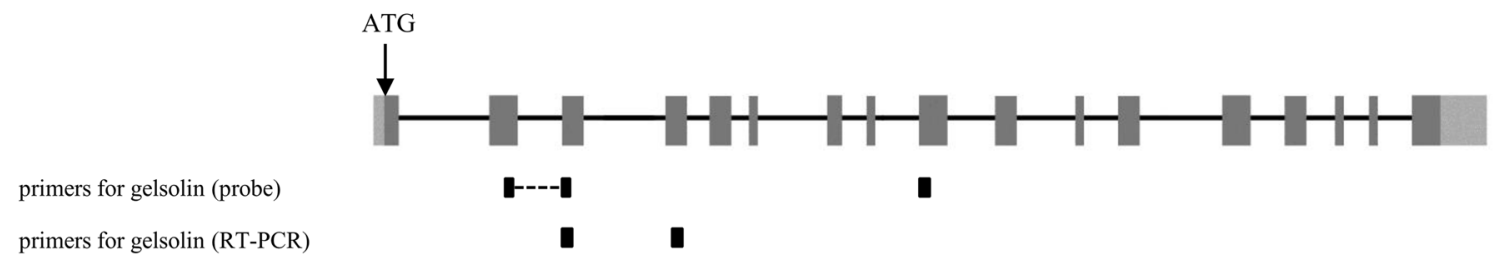

Fig. 1 Analysis of amino acid sequence of chicken gelsolin and molecular biological strategies for probe preparation and RT-PCR analysis. a Alignments of $\mathrm{N}$-termini of known and presumptive human gelsolin isoforms and chicken gelsolin precursor. Human gelsolin isoform b known as cytoplasmic gelsolin does not possess an additional amino acid sequence at $\mathrm{N}$-terminus. Thus, it was not subjected to this analysis. In cases of other human gelsolin isoforms, the length of additional amino acid sequence varies with the longest one for gelsolin isoform a described as plasma gelsolin. Amino acid

splanchnopleure, but not somatopleure in the posterior part of embryo (Fig. 2e, i, j). In older embryos at HH-stage 21, the expression pattern of $G S N$ is still very distinct (Fig. 2kr). High amount of $G S N$ transcript were detected in cranial and dorsal root ganglia (Fig. 2k-r), the olfactory tract (Fig. 21), the atrioventricular canal (Fig. 2l), the eye (Fig. 2k, 1), and limbs mesenchyme (Fig. 2k). Analysis of a series of vibratome sections of chicken embryo shown in Fig. 2k revealed strong GSN expression not only in dorsal root ganglia but also in the sympathetic trunk (Fig. 2n-r). Interestingly, there is also a prominent presence of GSN transcript in the neuroepithelial and the mantle layers of the neural tube (Fig. 2q). In the chicken embryo at this developmental stage, we further observe $G S N$ expression in sequences alignments were done with the help of the MAFFT program. "Asterisk" means identical, "colon" represents conserved substitutions, "dot" means semi-conserved substitution. b Schematic map of chicken gene coding for gelsolin precursor (gene id: 395774, Pubmed). Gray boxes represent exons and pale gray boxes reflect UTRs. Sites, to which primers used for riboprobes preparation and for RT-PCR analysis anneal, are shown schematically as bold bars. Note that the probe recognizing gelsolin spans exons 2-9. Primers for RTPCR reaction detecting gelsolin span exons 3-4

mesenchymal cells surrounding the aorta and in dermal cells (Fig. 2q). In the chicken embryo at HH-stage 22 (Fig. 2s-u), the GSN expression pattern is slightly changed in comparison to stage HH21 chicken embryo. The signal in the cranial ganglia is not so distinct any more except for the trigeminal ganglion and a more prominent staining of pharyngeal arches is to be seen (Fig. 2t). Still, a strong $G S N$ expression in dorsal root ganglia, the sympathetic trunk and limbs mesenchyme was observed. In chicken embryo at HH-stage 25 (Fig. $2 \mathrm{v}-\mathrm{x}$ ), we could observe the presence of GSN transcript especially in head and limbs mesenchyme, region of visceral arches, and dorsal root ganglia. The staining pattern of dorsal root ganglia in the proximal part (Fig. $2 \mathrm{w}$ ) of the trunk was different from that 
in the posterior part (Fig. 2x). In vibratome sections of chicken embryo shown in Fig. 2v, we observed distinct GSN expression in dorsal root ganglia, dermal cells, and in the developing eye (Fig. 2y, z).

In older chicken embryos at HH-stage 29, we observed a strong expression of GSN in the eye, limb bud mesenchyme, and the dermis (Fig. 3a). Later in the development at $\mathrm{HH}-$ stage 33, the presence of gelsolin mRNA was detected in the limb bud mesenchyme and eye (Fig. 3b). However, the overall signal was weaker when compared to younger stages (Fig. 3a). Next, we examined very detailed 10-day-old chicken embryo (HH-stage 36). We found strong GSN expression in the outer cell layer of the feather buds (Fig. 3c, $\left.\mathrm{e}, \mathrm{e}^{\prime}\right)$, the cochlea of ear, the nictitating membrane and at peripheries of scleral ossicles (Fig. $3 \mathrm{~d}, \mathrm{~d}^{\prime}$ ). To gain more information about $G S N$ expression in organs and tissues of developing chicken embryo prior to in situ hybridization, we longitudinally cut chicken embryos into two parts. We found out that there are high amounts of GSN transcripts in the olfactory bulb, the nasal conchae, the developing comb, eye muscles (Fig. 3f, g), and meninges (Fig. 3h), where we can observe a line-patterned staining. We observed an interesting pattern of most probably inter-innervation of neck skeletal muscles (Fig. 3i) and back skeletal muscles, e.g., iliotrochantericus muscle (Fig. 3j). As in younger chicken embryos, we could observe a strong expression of GSN in the dorsal root ganglia, especially in cell bodies of neurons and spinal nerves crossing the dorsal root ganglia, but not in the more distal branches (rami) of the spinal nerves (Fig. 3j, j'). Presence of GSN transcript is manifested also in a set of cells localized in the atrial part of the heart (Fig. 3k), on the surface of proventriculus, gizzard, spleen, intestine, and pancreas. The signal for gelsolin apparently localized within smooth muscle layers of circular and longitudinal muscles of intestine. A characteristic staining pattern on the surface of gizzard suggests stained structures belong to enteric nervous system (Fig. 31-n). In situ hybridization experiments with the sense probe served as negative controls and gave no specific stainings (Online Resource 1, Fig. S2).

\section{RT-PCR and western blotting experiments}

To confirm results from in situ hybridization experiments, we next performed RT-PCR analysis to detect GSN mRNA. In Fig. 1b, the sites to which primers, which were used in this analysis, anneal are shown. We analyzed the obtained cDNA libraries from chicken embryos at different stages and several organs of chicken embryo at HH-stage 36. Gelsolin mRNA was present at all tested stages of chicken embryo development. Interestingly, we noted less PCR products for GSN transcript in chicken embryo at HH-stage 25 than in earlier stages, whereas $A C T B$ PCR product amount rose proportionally to the developmental stage
(Fig. 4a). In all tested organs of chicken embryo at $\mathrm{HH}$ stage 36, the presence of GSN transcript was observed; however, its amount varied among tissues and we observed highest amount of the product in skin, eye, meninges, heart, and lung. Upon identification of antibodies recognizing avian gelsolin (Online Resource 1, Fig. S3A), we performed Western Blot analysis of lysates of younger chicken embryos and organs of chicken embryo at $\mathrm{HH}$-stage 36 (Fig. 4b). Gelsolin was detected at protein level in chicken embryos at all tested stages. In organs of stage 36 chicken embryos, we noted different amounts of gelsolin. Gelsolin was abundantly found in the eye, meninges, gizzard, and small intestine. Moderate amount of gelsolin was observed in the skin, heart, spleen, skeletal muscles, and mesonephros. Low amounts of gelsolin were detected in brain, lung, liver, and metanephros. These results reflect RT-PCR analysis and the results obtained from in situ hybridization experiments. Additionally, we have probed the membranes with antibodies recognizing either $\beta$ actin or $\beta$ tubulin as reference proteins. The amount of $\beta$ actin or $\beta$ tubulin differed between tested tissues, although we loaded on every lane $30 \mu \mathrm{g}$ of protein. It was shown for several times neither $\beta$ actin nor $\beta$ tubulin are suitable loading controls (Dittmer and Dittmer 2006; Eaton et al. 2013) and amounts of $\beta$ actin or $\beta$ tubulin are unequal between, e.g., different tissues or normal and pathologically changed samples of the same tissue origin (Eaton et al. 2013). In our case, there was for example trace amount of $\beta$ actin in tissue extract of heart isolated from 10-day-old chicken embryo (Fig. 4b). Probably at this stage of development most of actin pool in chicken heart consists already of $\alpha$ cardiac actin. On the other hand, the highest amount of $\beta$ tubulin was observed in the brain extract (Fig. 4b). Corresponding membranes to the WB analysis shown in Fig. 4b were subjected to a total protein analysis by staining with Ponceau $S$ (Online Resource 1, Fig. S3B). Although it seems on some lanes (spleen or skeletal muscle) there was less protein loaded, it does not have to mean that in the initial protein mixture subjected to the WB analysis, there was an unequal amount of proteins. One has to keep in mind that we denatured the proteins by boiling them at $95{ }^{\circ} \mathrm{C}$ for $10 \mathrm{~min}$. Membraneassociated proteins with a high degree of hydrophobicity aggregate under these conditions (Schägger 2006) and get stuck in the stacking gel resulting in their absence in the separating gel and finally on the membrane. Also, very small proteins $(<10 \mathrm{kDa})$ can be problematic, when standard SDS-PAGE (Laemmli 1970) is applied (Schägger 2006). Here, we have used standard SDS-PAGE, because gelsolin, $\beta$ actin, and $\beta$ tubulin are well resolved under conditions of standard denaturing electrophoresis. One should consider our WB analysis as an overview of expression level of these three proteins in different tissues of developing chicken embryo at HH-stage 36 (10 days). 

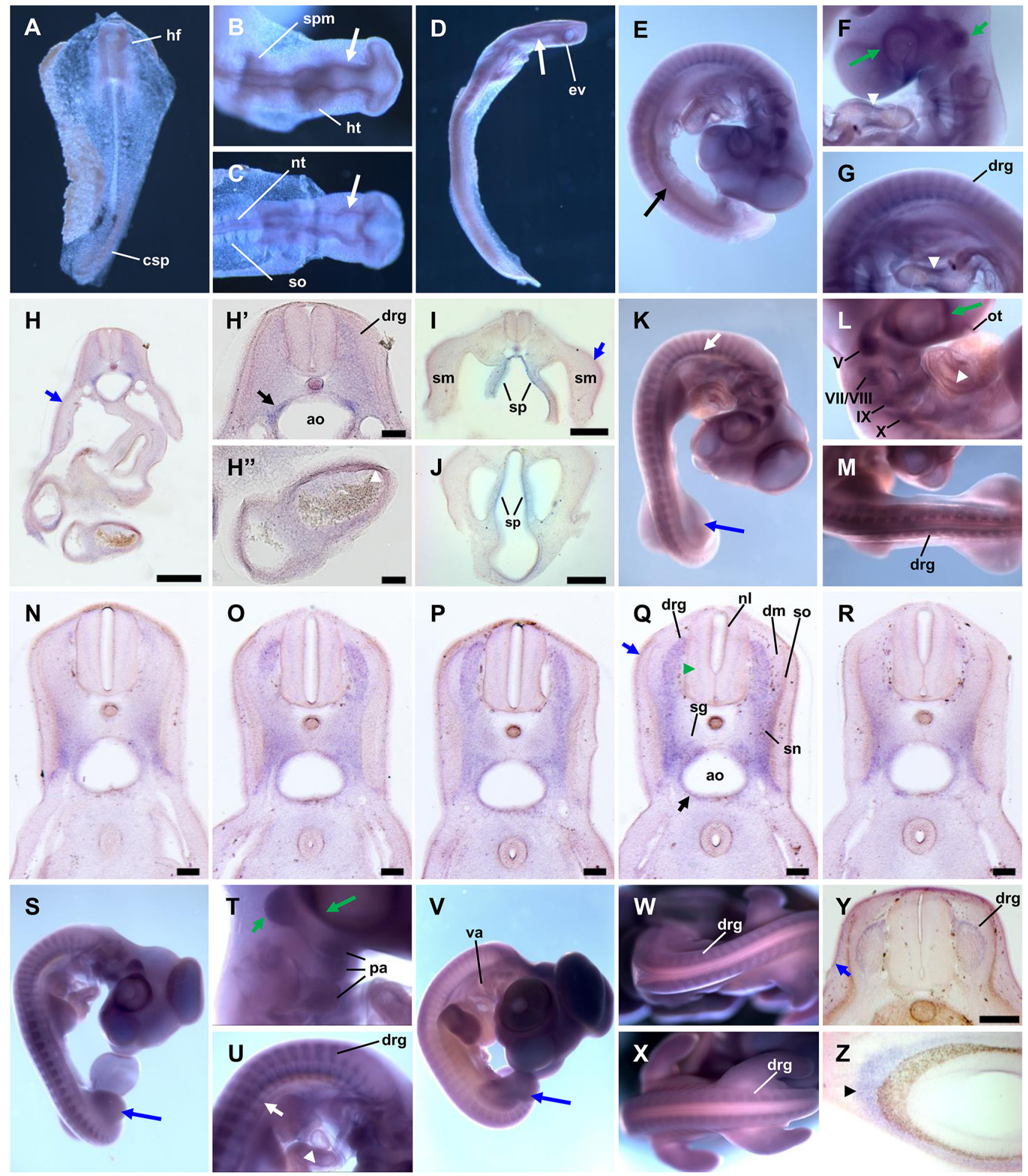

Immunohistochemical stainings

Having antibodies recognizing chicken gelsolin (Fig. 4 and Online Resource 1, Fig. S3A), we decided to analyze paraffin sections stained with these antibodies and counterstained with Mayer's hematoxylin solution to gain more information about the distribution of gelsolin at protein level in embryos at stages HH33 and HH36. Analysis of stained frontal sections of chicken embryo at $\mathrm{HH}$-stage 33 revealed the presence of high gelsolin 
4Fig. 2 In situ hybridization experiments with the probe recognizing gelsolin transcript to whole mount chicken embryos at early stages. a$\mathbf{g}, \mathbf{k}-\mathbf{m}, \mathbf{s}-\mathbf{x}$ Whole mount in situ hybridization; $\mathbf{h}-\mathbf{j}, \mathbf{n}-\mathbf{r}, \mathbf{y}, \mathbf{z}$ : vibratome sections. a Stage HH8 embryo showing expression of GSN at a relatively low level and uniformly distributed within embryo with stronger expression in the head folds and the caudal segmental plate. b-d Stage HH10-11 embryo. Distinct expression of GSN is observed in the eye and brain vesicles (long white arrows), the midbrain, the heart tube, the splanchnic mesoderm, and the neural tube. Note the absence of GSN expression in the somites. e-g Stage HH18 embryo. $G S N$ is highly expressed and predominantly present in the head mesenchyme, the eye cup (long green arrow), the atrioventricular canal (white arrowheads), cranial ganglia (short green arrow), dorsal root ganglia, and the splanchnopleure (long black arrow). hj Vibratome sections of the embryo shown in e-g. $\mathbf{h}^{\prime}-\mathbf{h}^{\prime \prime}$ Higher magnifications of $\mathbf{h}$. Note prominent GSN expression in a layer of mesenchymal cells surrounding aorta (short black arrow), the atrioventricular canal (white arrowhead), the splanchnopleure, and dermal cells underlying the epidermal ectoderm (short blue arrows). Note absence of signal in blood cells and the somatopleure. km Stage HH21 embryo. Expression pattern of GSN is significant and again high expression level is observed in the olfactory tract, cranial ganglia ( $V$ trigeminal, VII geniculate, VIII vestibular acoustic, IX petrosal, and $X$ nodose ganglia), dorsal root ganglia, the sympathetic trunk (short white arrow), the eye cup (long green arrow), the atrioventricular canal (white arrowhead), and limbs mesenchyme (long blue arrow). n-r Serial vibratome sections of embryo showed in $\mathbf{k}-\mathbf{m}$. Note strong $G S N$ expression in dorsal root ganglia, the spinal nerve, spinal ganglia, mesenchymal cells surrounding aorta (short black arrow), the neuroepithelial layer of neural tube, the mantle layer of neural tube (green arrowhead), and dermal cells underlying the epidermal ectoderm (short blue arrow). s-u Stage HH22 embryo. $G S N$ higher expression levels are found especially in pharyngeal arches, the eye (long green arrow), cranial ganglia (short green arrow), dorsal root ganglia, the sympathetic trunk (white short arrow), the atrioventricular canal (white arrowhead), and limbs mesenchyme (long blue arrow). $\mathbf{v}-\mathbf{x}$ Stage $\mathrm{HH} 25$ embryo. Relatively high $G S N$ expression is observed in the head, the eye, within limbs mesenchyme (long blue arrow), visceral arches and dorsal root ganglia, which staining pattern in the posterior part of embryo (x) is different in comparison to the proximal part of embryo (w). $\mathbf{y}$, $\mathbf{z}$ Vibratome sections of embryo showed in $\mathbf{v}-\mathbf{x}$. Note a moderate $G S N$ expression within boundaries of dorsal root ganglia and in dermal cells (short blue arrow). There is a strong GSN expression in the cells surrounding pigmented retina (black arrowhead). ao aorta, csp caudal segmental plate, $d m$ dermomyotome, $d r g$ dorsal root ganglia, $e v$ eye vesicle, $h f$ head fold, $h t$ heart tube, $n l$ neuroepithelial layer, $n t$ neural tube, ot olfactory tract, $p a$ pharyngeal arches, $s g$ spinal ganglia, $s m$ somatopleure, sn spinal nerve, spm splanchnic mesoderm, so somite, $s p$ splanchnopleure, $v a$ visceral arches. The presence of staining within vesicles in the head region is due to the probe trapping. Scale bars $h, i, j, y 1,000 \mu \mathrm{m}, h^{\prime}, h^{\prime \prime} 200 \mu \mathrm{m}, n-r 500 \mu \mathrm{m}$

amounts in the notochord/neural tube-especially in the ependymal layer of the neural tube, ganglia, dermomyotome, and under epidermis (Fig. 5a, c). Note the complete absence of signal for gelsolin in bone precursor tissue (Fig. 5c). In the brain, gelsolin was moderately present and relatively uniformly distributed (Fig. 5a, b). In the eye, we observed a strong signal for gelsolin within the iris and the lens. Intriguingly, the gelsolin rich cells were present in the basal layer of the lens epithelium, whereas the cells in the apical layer of the lens epithelium were devoid of gelsolin (Fig. 5d, e).

Because the results of in situ hybridization experiments suggested that $G S N$ is especially expressed in some tissues of ectodermal origin including neural crest-derived cells, we decided to get a closer look at the heads of chicken embryos at $\mathrm{HH}$-stage 36 . We observed a strong signal for gelsolin in several tissue types (Fig. 6 and Online Resource 1, Fig. S4). Interestingly, while analyzing transverse sections of neck, we noted a very high amount of gelsolin in cells adjacent to the basement membrane (Fig. 6a, b), in strips of cells within neck muscles (Fig. 6a, d), most probably in fibroblasts, which form ligaments (Fig. 6c) and in the cells within the vertebral cartilage (Fig. 6e). Analysis of head sagittal sections revealed the presence of gelsolin within the developing brain with significantly stronger presence of gelsolin in the optic nerve and presumably the pituitary gland (Fig. 6f, g, 1, m), meninges and the telencephalon (Fig. 61, m). High amounts of gelsolin in meninges, the telencephalon and branches of oculomotor nerve were also detected in analyzed frontal sections of chicken heads (Fig. 6n, p). Frontal section of embryo heads (Fig. 6h) showed high amounts of gelsolin in the optic nerve and the pecten (Fig. 6j) and in the cells within muscle fibers of ventral oblique muscle of the eye (Fig. $\left.6 h^{\prime}\right)$. High amounts of gelsolin were observed in tissues of the eye (Fig. 6h and Online Resource, Fig. S4F). Strong signal was noted in the vitreous chamber of eye (Fig. $6 h^{\prime \prime}$ ), the retina, the choroidea, the sclera (Fig. 6i and Online Resource 1, Fig. S4F), the iris, the conjunctiva (data not shown) and finally in the epithelial and endothelial layers of cornea, whereas the stroma of the cornea was gelsolin-free (Fig. 6k). Moreover, high amount of gelsolin was observed in brain pericytes (Online Resource 1, Fig. S4D), muscle-connective tissue in the walls of head vessels (Online Resource 1, Fig. S4E), nerves within head (Fig. 6n and Online Resource 1, Fig. S4I), olfactory bulb (Fig. 6h) and the olfactory epithelium of the nasal conchae (Online Resource 1, Fig. S4G, H). Interestingly, we noted different patterns of staining within muscles, i.e., all muscle fibers within the head were gelsolin-positive (Online Resource 1, Fig. S4B, C), whereas within neck musculature the staining showed a strip-like pattern (Fig. 6d and Online Resource 1, Fig. S4A). In some feather buds, we noted the absence of gelsolin at protein level (Fig. 6a), whereas in feather buds localized, e.g., on the head, we observed a strong gelsolin presence (Online Resource 1, Fig. S4J, K).

As a summary of GSN expression in chicken embryos between developmental days 1 and 10, we assembled the obtained data in a table (Table 2). 

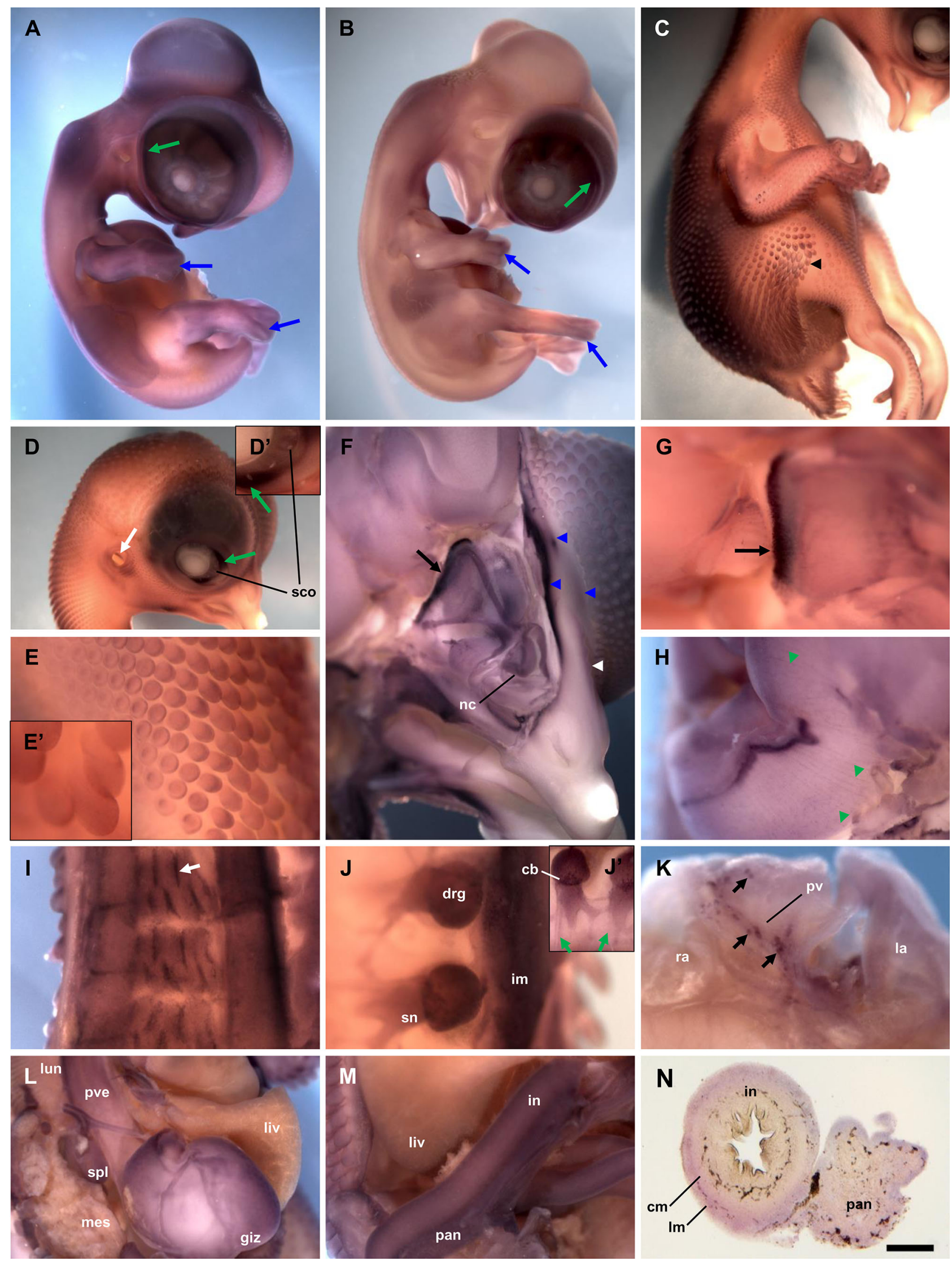
4Fig. 3 In situ hybridization experiments with the probe recognizing gelsolin transcript to whole mount chicken embryos at late stages. a$\mathbf{m}$ Whole mount in situ hybridization. $\mathbf{n}$ Vibratome section. a Stage HH29 embryo. High GSN expression is observed in the eye (green long arrow), within the developing skin and in limbs mesenchyme (long blue arrow). The presence of staining within vesicles in the head region is due to the probe trapping. b Stage HH33 embryo. Note the high GSN expression level in the eye (green long arrow) and limbs mesenchyme (long blue arrow). c-e Stage HH36 embryo. There is a strong signal for gelsolin mRNA observed in nictitating membrane (green long arrows), at peripheries of scleral ossicles, in cochlea of ear (white long arrow) and feather buds (black arrowhead and $\mathbf{e})$. $\mathbf{d}^{\prime}, \mathbf{e}^{\prime}$ Higher magnifications of $\mathbf{d}$ and $\mathbf{e}$, respectively. $\mathbf{f}-$ n Photos of cut longitudinal prior to the in situ hybridization embryo at HH36-stage. $\mathbf{f}-\mathbf{h}$ High GSN expression is observed in the olfactory bulb (long black arrow), the nasal conchae, eye muscles (blue arrowheads), the developing comb (white arrowhead) and meninges. Note a line-patterned staining within meninges (green arrowheads). i Stained presumptive inter-innervation of neck skeletal muscles (white short arrow). $\mathbf{j}$ There is a high GSN expression in dorsal root ganglia, spinal nerves and presumably nerves within iliotrochantericus muscle. Note absence of signal in the more distal branches of the spinal nerves (short green arrow). $\mathbf{j}^{\prime}$ Higher magnification of j. $\mathbf{k}$ Dorsal view of the atrial part of a heart, with strongly gelsolin mRNA-positive cells (short black arrows). l, m Note high GSN expression on the surface of proventriculus, gizzard, spleen, small intestine, and pancreas. n A vibratome section of intestine and pancreas shown in $\mathbf{m}$. There is observed a strong signal for gelsolin mRNA within circular and longitudinal muscles of the intestine wall. $\mathrm{cm}$ circular muscle, $c b$ cell bodies of neurons, $\mathrm{drg}$ dorsal root ganglia, giz gizzard, im iliotrochantericus muscle, in intestine, la left atrium, liv liver, $l m$ longitudinal muscle, lun lung, mes mesonephros, $n c$ nasal conchae, pan pancreas, $p v$ pulmonary vein, pve proventriculus, $r a$ right atrium, sco scleral ossicles, spl spleen, sn spinal nerve. Scale bar $n 1,000 \mu \mathrm{m}$

\section{Gelsolin in chicken brain development}

Because we have noted high GSN expression level especially in the head regions, we asked ourselves, if gelsolin is important for chicken brain development. For this purpose, we have generated plasmids coding for shRNAmirs targeting gelsolin mRNA. We have electroporated chicken embryos into brain vesicles at HH-stages 11-12 with plasmids solution. These stages are the most suitable for our approach, because the neural tube is already closed and the head of the embryo is still unturned. From HH-stage 14, it is impossible to electroporate the brain vesicles in ovo because the head is turned completely to the right, what makes impossible to perform electroporation of one side of the brain vesicles. To trigger expression of shRNAmirs and EGFP $12 \mathrm{~h}$ later, we have injected doxycycline between the embryo and yolk. After $24 \mathrm{~h}$, we photographed the embryos in ovo and harvested them. The embryos developed to HH-stages 18-20. We tried to incubate the embryos for longer times, but we were not successful. Two types of control experiments were carried out: (1) we did not induce expression of shRNAmirs and EGFP by applying doxycycline solution (Fig. 7b, c) or (2) we used plasmids coding scRNAmirs (Fig. 7d-g, 1-o). Following harvesting of the embryos, in situ hybridization experiments were performed. We used the probes recognizing mRNAs coding gelsolin and Cecr2. Expression of CECR2 was observed in the developing chicken brain (Chen et al. 2010), that is why we have used it as a brain marker to track potential morphological changes within the brains of manipulated embryos. We noted in embryos expressing a mixture of shRNAmirs targeting gelsolin mRNA lowered expression of the gene encoding gelsolin (Fig. 7i-k), but not of CECR2 (Fig. 7q-s). We observed a striking effect of GSN expression silencing concerning development of mesencephalon, i.e., the electroporated part of the mesencephalon seemed to be underdeveloped resulting in a shortened right part of the mesencephalon in comparison to the non-electroporated, left part of the mesencephalon (Fig. 7i-k, q-s, t). We did not note the described effect in control experiments (Fig. 7c, e-g, m-o, t).

\section{Discussion}

There is very little data concerning gelsolin in chicken development. Heller et al. (1998) identified mRNAs of a group of proteins highly abundant in the inner ear of the chicken. One of "tissue-specific" mRNAs found in the homogeneous cells was mRNA for a protein named by the authors homogenin. The researchers, applying Northern blot analysis, found out homogenin's transcript was present in high amount also in the heart and the skin and in lower amount in muscles, the cerebellum, the forebrain, and the eye. However, the comparison of amino acid sequences of chicken gelsolin and homogenin revealed homogenin is $100 \%$ identical to chicken gelsolin (Online Resource 1, Fig. S5). In 2013, Korte and colleagues published proteomic data confirming for the first time the presence of gelsolin at protein level in chicken. Their analysis suggests gelsolin is potentially important for development of chicken bursa of Fabricius. Interestingly, they showed the highest amount of gelsolin at embryonic day 18 suggesting gelsolin could be of significant relevance for the development of bursa of Fabricius during bursal stage. Lower amounts of gelsolin were noted in the prebursal and postbursal stages.

In this paper, we show for the first time the distribution of gelsolin not only at transcript but also at protein level in the developing chicken embryo from embryonic day 1 (E 1) to E 10. At the early stages of the embryonic development, i.e., HH10-11, we observed the presence of gelsolin mRNA in the eye and brain vesicles, the midbrain, the heart tube, the splanchnopleure and the neural tube, but not in the somites. Later on, at the HH18 stage GSN was 
A

GSN

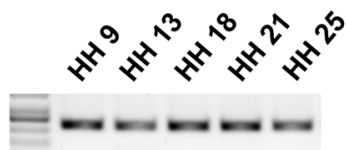

$3 \mathrm{D}$ view

$\rightarrow \rightarrow m-$

АCTB

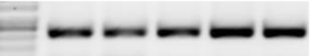

3D view

$\rightarrow-m$

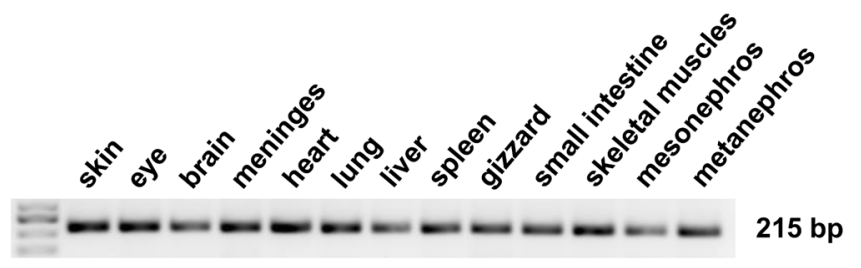

3D view

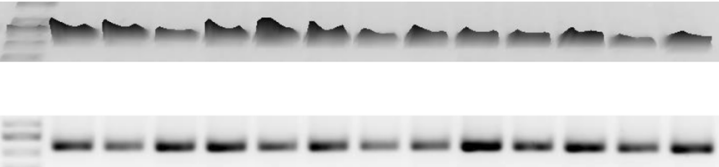

3D view

$-m-m-m \rightarrow \infty$

B

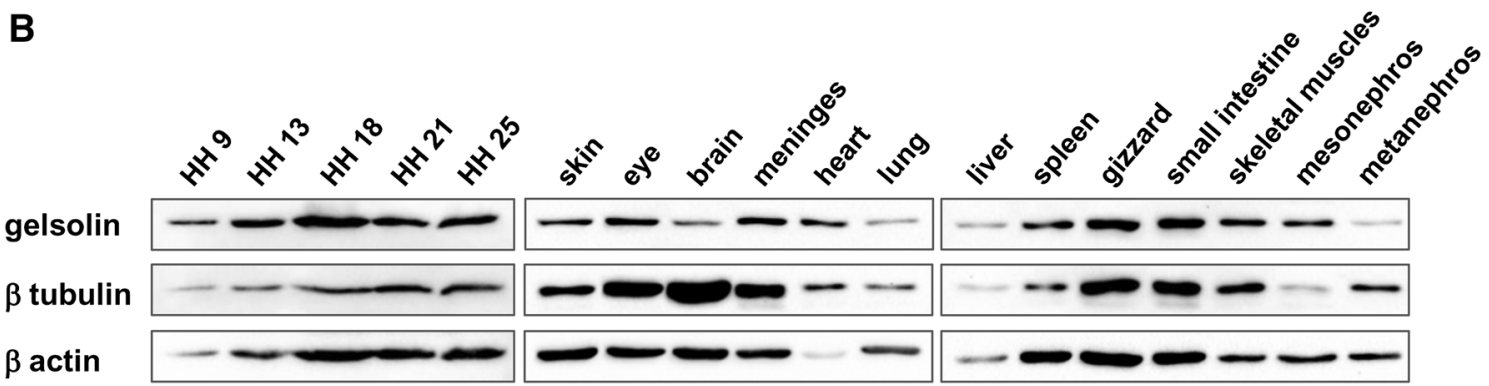

Fig. 4 RT-PCR and Western blot analysis of gelsolin expression in chicken embryos and organs from chicken embryos at stage HH36. a Horizontal DNA electrophoresis of PCR products. As templates for PCR served cDNAs obtained from chicken embryos at different developmental stages (HH9-25) and tissues removed from chicken embryo at $\mathrm{HH} 36$ stage. PCRs were carried out using primers spanning exons recognizing GSN mRNA. ACTB, gene coding $\beta$ actin served as a reference gene. Note different expression levels of $G S N$ and $A C T B$ genes in tested tissues. We observed highest amount of GSN product in skin, eye, meninges, heart, and lung. b Western blot analysis of protein extracts from chicken embryos at different developmental stages (HH9-25) and tissues removed from chicken embryo at HH36 stage for presence of gelsolin at protein level. High amount of gelsolin was in the eye, meninges, gizzard and small intestine; moderate amount of gelsolin was observed for skin, heart, spleen, skeletal muscles, and mesonephros and the lowest amount of gelsolin was detected in brain, lung, liver, and metanephros. As reference $\beta$ tubulin and $\beta$ actin were taken. $30 \mu \mathrm{g}$ of protein was loaded on every line

especially highly expressed in several tissues of ectodermal origin including neural crest (NC) derivatives, which give origin to many tissues within the head (Le Douarin et al. 2004; Dupin and Sommer 2012). We observed the presence of gelsolin at mRNA and protein level only in a part of tissues of ectodermal origin: the olfactory epithelium, the olfactory bulb and tract, the lens, elements of the optic cup, the optic nerve, branches of the oculomotor nerve, telencephalon, and presumptive the pituitary gland. Interestingly, we found out that $G S N$ was expressed in all analyzed by us NC-derived cell lineages, e.g., in the endothelium of the cornea, the cochlea, pericytes of the brain; meninges, walls of blood vessels, developing dermis and muscles within the head. According to the literature, NC derivatives are found, e.g., in heart (Deal et al. 2006; Levin et al. 2009; Simon et al. 2012), eye structures (Simon et al. 2012; Dupin and Sommer 2012; Swamynathan 2013), cochlea (Simon et al. 2012), skin and feather buds (melanocytes), Schwann cells of gut, stomach and sciatic nerve (Hari et al. 

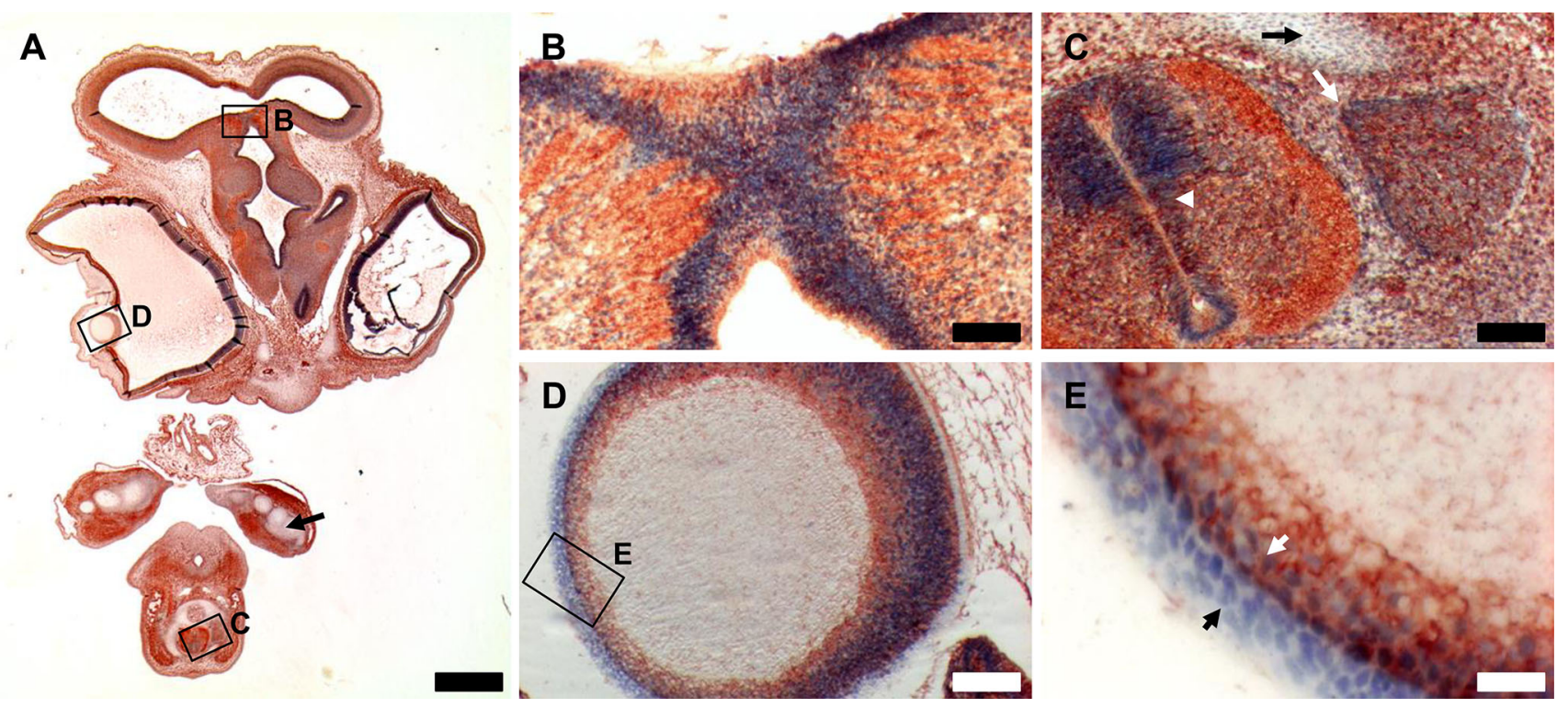

Fig. 5 Immunohistochemical analysis of chicken embryo sections at stage HH33. Sections of chicken embryo were stained with rabbit monoclonal anti-gelsolin antibodies and counterstained with Mayer's hematoxylin solution. a Frontal section of whole embryo. Note no signal in bone precursor tissues (black arrow). b-e Higher magnifications of section presented in $\mathbf{a}$. b A strong signal was present in brain tissue. $\mathbf{c}$ There is high gelsolin amount in the ependymal layer of the neural tube (white arrowhead) and the dorsal root ganglion (white arrow). There is no signal for bone precursor tissue (black arrow). d There is high amount of gelsolin in the developing lens. e Higher magnification of the section presented in $\mathbf{d}$. Note the basal cell layer of the lens epithelium is rich in gelsolin (short white arrow), whereas the apical cell layer of the lens epithelium is devoid of gelsolin (short black arrow). Scale bar a 1,000 $\mu \mathrm{m}, b-d 90 \mu \mathrm{m}$, e $25 \mu \mathrm{m}$
2012; Simon et al. 2012; Dupin and Sommer 2012), meninges, pericytes of the brain (Le Douarin et al. 2004; Simon et al. 2012; Dupin and Sommer 2012), muscleconnective tissue walls of blood vessels within the head (Le Douarin et al. 2004) and ensheathing cells within the olfactory nerve (Dupin and Sommer 2012).

Although, in the brain of older chicken embryos (E 10), we observed a higher gelsolin expression only in the brain pericytes and telencephalon, but not in other brain cell types, we decided to test if gelsolin is important for chicken brain development. We silenced GSN expression by electroporation of the brain vesicles of chicken embryo at $\mathrm{HH}$ stages 11-12 with plasmids coding shRNAmirs targeting gelsolin mRNA. Because of technical limitations, we could analyze only young embryos. However, we were able to observe a morphological effect of GSN expression silencing. In most of the analyzed embryos expressing shRNAmirs targeting gelsolin mRNA, the mesencephalon was shorter in comparison to control embryos. This suggests gelsolin is crucial for proper development of the chicken brain.

The GSN expression pattern presented on vibratome sections of chicken embryos at $\mathrm{HH}$-stage 21 resembles that one described by Adameyko et al. (2009). The authors showed melanocytes in birds and mammals originate in two ways, either in dorso-lateral or ventral pathway. In the former case, melanoblasts delaminate directly from the roof plate of neural tube and in the latter case melanocytes are derived from Schwann cell precursors (SCPs) surrounding peripheral nerves. The ventral pathway gives rise to melanocytes found in the ventral part of the body and in the limbs both within epidermis as well as extracutaneous. The exact mechanism deciding if SCPs will become Schwann cells or melanocytes is still to be elucidated. The GSN expression pattern observed by us especially around developmental stage $\mathrm{HH} 21$, where we observed a strong signal for gelsolin mRNA in the dorsal root ganglia, spinal nerves, and its branches, resembles expression pattern of SOX2 and SOX10 genes, which products are involved in the peripheral nerves and melanocyte development (Adameyko et al. 2012). Moreover, we noted enhanced GSN expression within the developing dermis corroborating our notion that GSN is expressed most probably also in melanoblasts migrating along the dorso-lateral pathway to their destinations. Altogether it supports again our thesis that GSN expression is enhanced in the NC-derived cells.

Tanaka and Sobue (1994) observed in rats the presence of gelsolin in Schwann cells of PNS and in some structures of the CNS, although with different abundancy. Highest amount of gelsolin was observed in basal regions of the brain. A detailed analysis revealed gelsolin was localized in the myelin sheath of oligodendrocytes and Schwann cells in the CNS and PNS, respectively. GSN expression was changing in time and the highest amount of gelsolin at 
protein levels in the brain were observed 3-4 weeks after birth, upon this period, the gelsolin amount was decreased; however, even in 6-month-old rats, gelsolin was detectable in oligodendrocytes. Gelsolin was observed neither in neurons nor in other types of glial cells. We noted also that most probably innervation of proventriculus, gizzard, spleen, intestine, and pancreas was positive for the presence of gelsolin mRNA, which again is in accordance with the literature saying GSN expression is observed in Schwann cells in the peripheral nerves (Tanaka and Sobue 1994). Although high gelsolin amounts were found in the myelin sheath producing cells, it seems that this ABP is not essential for the remyelination process after nerve injury of peripheral nerves in mouse (Gonçalves et al. 2010). Our immunohistochemical analysis of the developing chicken brain revealed higher GSN expression levels within telencephalon and the presumptive pituitary gland, whereas gelsolin-positive pericytes were found in the whole brain. We did not observe other cells, e.g., oligodendrocytes in the brain of E10 chicken embryo, which would be strongly gelsolin-positive. Although oligodendrocytes are not of neural crest origin, it is surprising that in the adult, but not embryonic mouse oligodendrocytes, SOX10 expression reporter cells were noted (Simon et al. 2012). It could be possible that first upon initiation of SOX10 expression in the brain of hatchlings, GSN expression in oligodendrocytes would begin. Due to that it could be possible that GSN expression is controlled by a signaling pathway involving Sox10 in both cell types: oligodendrocytes and Schwann cells. Interestingly, Sox10 is also crucial for myelin sheath maintenance in adult mice (Bremer et al. 2011). Tanaka and Sobue (1994) tested rats after birth, but there were no experiments performed on embryos at different developmental stages. That is why it is not known, if gelsolin is present in the rat embryonic oligodendrocyte lineage. Intriguing is also the fact that in the adult mouse cranial pericytes SOX10 is not expressed, whereas it is in the embryonic pericytes (Simon et al. 2012). Up to date, there are no studies concerning the correlation of GSN expression with SOX10 expression. SOX10 expressing cells were found in mouse embryonic cochlea, cranial, and dorsal root ganglia, skin, gut, stomach, eye, hair follicles, melanocytes, peripheral nerves, and adrenal gland (Simon et al. 2012). We observed enhanced $G S N$ expression in the same tissues of developing chicken embryo except for adrenal gland, which was not analyzed by us. The presumption that Sox 10 could influence GSN expression is additionally supported by the fact that in patients with schizophrenia the SOX10 methylation level was inversely correlated with the expression level of several "oligodendrocyte" genes including GSN (Iwamoto et al. 2005). We noted decreased GSN expression and gelsolin amount in several melanoma cell lines in comparison to normal
Fig. 6 Immunohistochemical analysis of chicken embryo sections at stage HH36. Sections of chicken embryo were stained with rabbit monoclonal anti-gelsolin antibodies and counterstained with Mayer's hematoxylin solution. a Transverse section of the neck. b-d Higher magnifications of section presented in $\mathbf{a}$. $\mathbf{b}$ Note high gelsolin amount in the cells layer (black arrow) adjacent to the basement membrane. c There was a strong signal for gelsolin in most probably fibroblasts forming ligaments. d Within neck muscles there were strips of cells strongly positive for gelsolin (white arrowheads). e The cells within forming vertebra exhibited strong gelsolin presence (black arrowheads). f Sagittal section of the head. g Higher magnification of section presented in $\mathbf{f}$. Note higher amount of gelsolin in the optic nerve and presumably the pituitary gland than in the rest of cerebral hemisphere. $\mathbf{h}$ Frontal section of the head. $\mathbf{h}^{\prime}-\mathbf{k}$ Higher magnifications of the section presented in $\mathbf{h} . \mathbf{h}^{\prime}$ Note a strong signal for gelsolin in muscle fibers of the external eye muscle. $\mathbf{h}^{\prime \prime}$ There was relatively high amount of gelsolin in the vitreous chamber of the eye. $\mathbf{i}$ In all layers of the eye retina, we noted gelsolin presence including the retinal pigment epithelium (short black arrow). j Note high amount of gelsolin in the optic nerve and the pecten. $\mathbf{k}$ In the epithelial layer (green arrow) and in the endothelial layer (white arrow) of the cornea, there was detected a very high gelsolin level. 1 Sagittal section of the head. $\mathbf{m}$ Higher magnification of section presented in $\mathbf{l}$. The cells building meninges exhibit high amount of gelsolin. Note high amount of gelsolin in telencephalon. $\mathbf{n}$ Frontal section of head. Again high amount of gelsolin was observed in the telencephalon, meninges within ventricles and in branches of oculomotor nerve (green arrowheads). o, $\mathbf{p}$ Higher magnifications of the section presented in n. High amount of gelsolin was observed in meninges between two hemispheres. $c c$ central canal, $c e r$ cerebellum, $g c l$ ganglion cell layer, ipl inner plexiform layer, inl inner nuclear layer, lol lumen of optic lobe, $l v$ lateral ventricle, men meninges, $o b$ olfactory bulb, on optic nerve, onl outer nuclear layer, pec pecten, $p g$ pituitary gland, $p r l$ photoreceptor layer, rpe retinal pigment epithelium, tel telencephalon, $t v$ third ventricle. Scale bar a $500 \mu \mathrm{m}, b-e, h^{\prime}-h^{\prime \prime}, i, k, m, o-p 25 \mu \mathrm{m}$, $f 2,000 \mu \mathrm{m}, g 200 \mu \mathrm{m}, h, l, n 1,000 \mu \mathrm{m}, j 60 \mu \mathrm{m}$

melanocytes (our unpublished data), corroborating the thesis that gelsolin is a tumor suppressor ( $\mathrm{Li}$ et al. 2012). Even though gelsolin amounts were decreased in human melanoma cells, they expressed $G S N$ at a relatively higher level than other tumor types (our unpublished data) (Litwin et al. 2012). Interestingly, it was reported SOX10 is expressed in melanoma cells (Deal et al. 2006; Shakhova et al. 2012), where it is apparently involved in formation and progression of melanoma (Shakhova et al. 2012). Intriguingly, in situ hybridization experiments revealed a population of gelsolin-positive cells in the upper part of the chicken heart at E10 (HH36). NC-derived cells were found in the corresponding region in the mouse heart (Deal et al. 2006; Levin et al. 2009). These cells apart from Sox10were Dct-, Mitf-, and Tyr-positive suggesting they are melanocyte-like. They also expressed adrenergic and muscarinic receptors. This together with the fact these cells most probably directly contact both autonomic nerves and cardiomyocytes suggests these melanocyte-like cells could be arrhythmogenic triggers (Levin et al. 2009). It is of course possible that other signaling pathways play a role in 

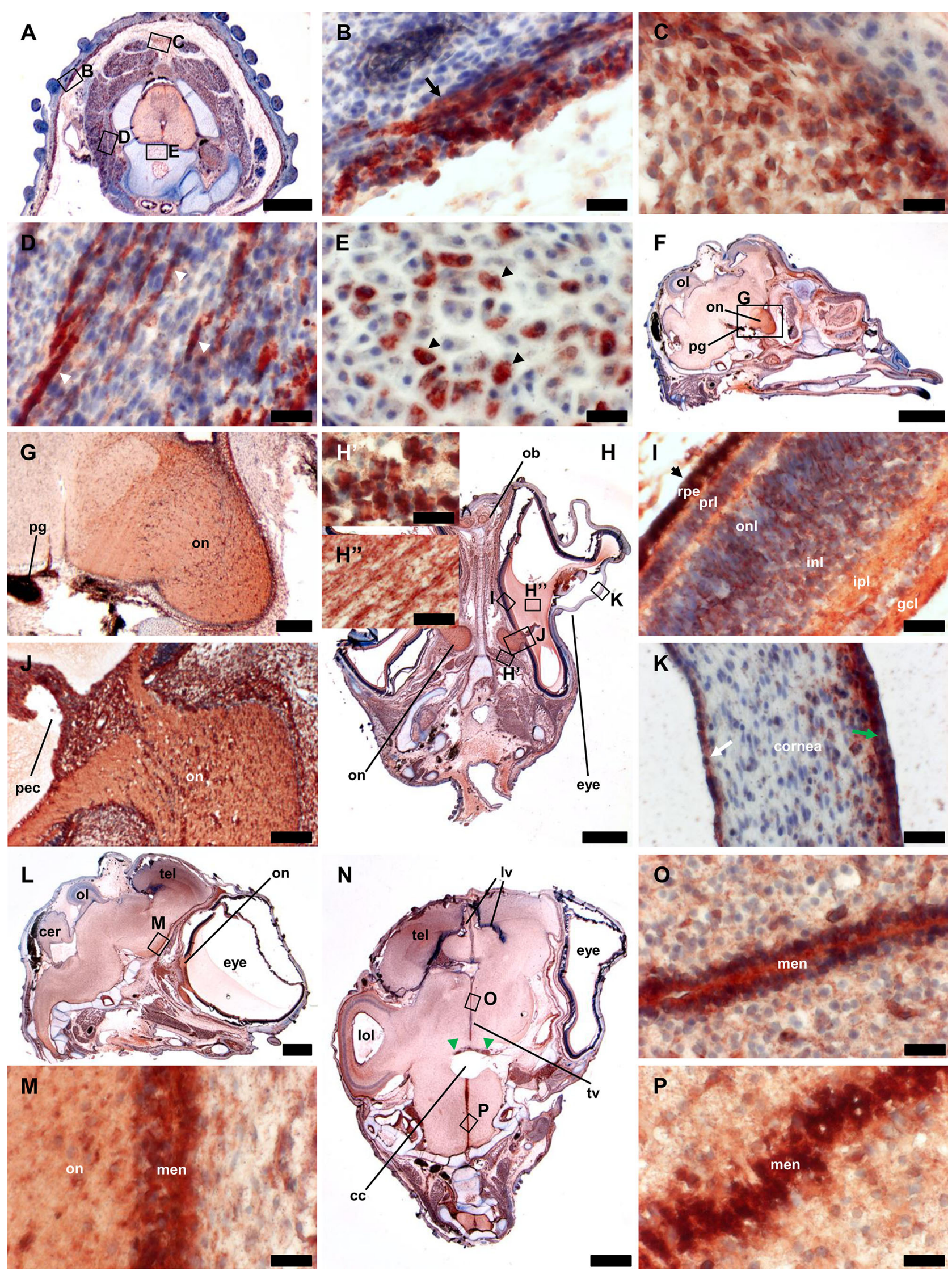
Table 2 Expression of GSN in tissues of analyzed embryos at $\mathrm{HH}$ stages 8-36 (E 1-10)

\begin{tabular}{|c|c|}
\hline HH-stage (E) & Tissue \\
\hline HH-stage 8 (E 1) & $\begin{array}{l}\text { Head fold }{ }^{\mathrm{a}} \text {, caudal segmental plate }{ }^{\mathrm{a}} \text {, whole } \\
\text { embryo analysis } \mathrm{b}, \mathrm{c}\end{array}$ \\
\hline $\begin{array}{l}\text { HH-stage 10-11 } \\
\quad \text { (E 1.5-2) }\end{array}$ & $\begin{array}{l}\text { Eye vesicle }{ }^{\mathrm{a}} \text {, brain vesicles }{ }^{\mathrm{a}}, \text { midbrain }^{\mathrm{a}} \text {, heart } \\
\text { tube }^{\mathrm{a}}, \text {, splanchnic mesoderm }^{\mathrm{a}} \text {, neural tube } \\
\text { whole embryo analysis }\end{array}$ \\
\hline HH-stage 18 (E 3) & $\begin{array}{l}\text { Head mesenchyme }{ }^{\mathrm{a}} \text {, eye cup }{ }^{\mathrm{a}} \text {, atrioventricular } \\
\text { canal }^{\mathrm{a}} \text {, cranial ganglia }{ }^{\mathrm{a}} \text {, dorsal root ganglia } \\
\text { splanchnopleure }^{\mathrm{a}}, \text { mesenchymal cells }^{\mathrm{a}} \text {, } \\
\text { surrounding aorta }^{\mathrm{a}} \text {, atrioventricular canal } \\
\text { dermal cells underlying the epidermal } \\
\text { ectoderm }^{\mathrm{a}}, \text { whole embryo analysis }\end{array}$ \\
\hline $\begin{array}{l}\text { HH-stage } 21-22 \\
\quad \text { (E 3.5) }\end{array}$ & 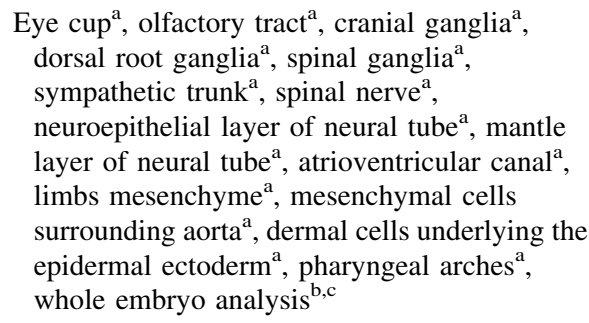 \\
\hline HH-stage 25 (E 5) & 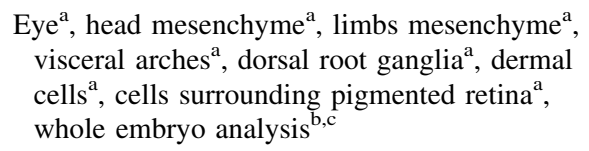 \\
\hline $\begin{array}{l}\text { HH-stage } 29(\mathrm{E} \\
6-6.5)\end{array}$ & $\begin{array}{l}\text { Eye }^{\mathrm{a}} \text {, within the developing } \text { skin }^{\mathrm{a}} \text {, limbs } \\
\text { mesenchyme }^{\mathrm{a}}\end{array}$ \\
\hline HH-stage 33 (E 8) & $\begin{array}{l}\text { Eye structures } \\
\text { ependymal layer of neural tube }{ }^{\mathrm{d}}, \text { dorsal root }^{\mathrm{a}} \text {, } \\
\text { ganglia }^{\mathrm{d}}\end{array}$ \\
\hline $\begin{array}{l}\text { HH-stage } 36(\mathrm{E} \\
10)\end{array}$ & 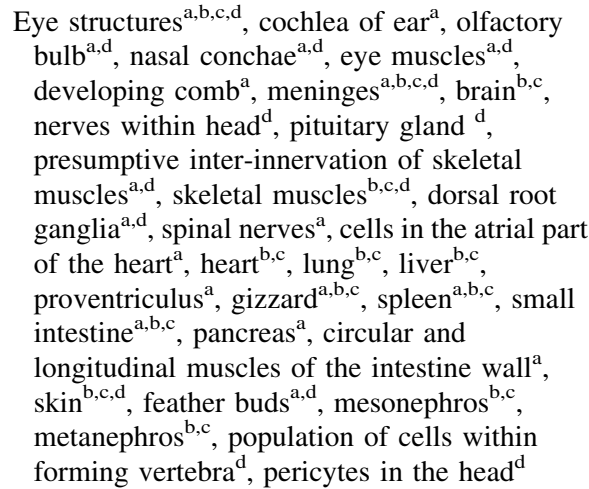 \\
\hline
\end{tabular}

\footnotetext{
${ }^{a}$ In situ hybridization

b RT-PCR

c WB

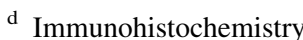

neural crest cells fate regulation (Milet and Monsoro-Burq 2012) and thus upstream of Sox10 could regulate GSN expression during embryonic development and formation of melanocytes and melanoma in adult organisms.

Although gelsolin is considered as a tumor suppressor in many types of malignancies, e.g., breast, bladder, colon, gastric, kidney, lung, oral, ovarian, pancreatic, and
Fig. 7 Analysis of electroporated chicken embryos expressing EGFP, scRNAmirs, or shRNAmirs targeting gelsolin mRNA. a A diagram showing $\mathrm{HH}$-stages, at which embryos were electroporated, treated with doxocycyline and harvested. $\mathbf{b}, \mathbf{d}, \mathbf{h}, \mathbf{l}, \mathbf{p}$ Photos of EGFP fluorescence taken in ovo. $\mathbf{c}, \mathbf{e}-\mathbf{g}, \mathbf{i}-\mathbf{k}, \mathbf{m}-\mathbf{o}, \mathbf{q}-\mathbf{s}$ Whole mount in situ hybridization. $\mathbf{c}, \mathbf{e}-\mathbf{g}, \mathbf{m}-\mathbf{o} G S N$ probe was used. $\mathbf{i}-\mathbf{k}, \mathbf{q}-\mathbf{s} C E C R 2$ probe was used. b-c Control experiment showing an electroporated embryo without triggered expression of shRNAmirs targeting gelsolin. Note no fluorescence signal of EGFP, no changes within right part of mesencephalon (green line) and unaltered GSN expression level in both parts of optic tectum (green arrows). d-g Embryo expressing scRNAmirs and EGFP (d). There are no changes within right part of mesencephalon (e, green line) and no decrease in GSN expression within optic tectum (green arrows). $\mathbf{h}-\mathbf{k}$ Electroporated embryo expressing shRNAmirs and EGFP (h). Note shortened right part of mesencephalon (i, red line) and diminished GSN expression within right part of optic tectum (red arrow), but not the left one (green arrow). The changes in the GSN expression level in the right part of the optic tectum were observed, when the embryo was photographed from the left, non-electroporated side of the embryo (k). In contrast, no changes in GSN expression level in non-electroporated, left side of the embryo were observed from the right, electroporated side of the embryo (j). l-o Embryo expressing scRNAmirs and EGFP (l) showed no changes in the right part of the mesencephalon ( $\mathbf{m}$, green line $)$ and no decrease in CECR2 expression level (white arrows). p-s An embryo expressing shRNAmirs and EGFP (p). Note the changed structure of the right part of the mesencephalon ( $\mathbf{q}$, red line), but there are no alterations in expression level of CECR2 (white arrows). t Statistical summary of abundance of observed effect, i.e., shortened right part of mesencephalon. $e$ eye, $m c$ mesencephalon, op otic placode/vesicle

prostate cancers (reviewed by $\mathrm{Li}$ with colleagues ( $\mathrm{Li}$ et al. 2012)), there is very little known about gelsolin in CNS and PNS tumors. Ohnishi et al. (2009) reported gelsolin could be a potential marker of astrocytomas, since gelsolin amount was inversely correlated with tumor aggressiveness as stated by analyzing cerebrospinal fluid of patients with astrocytoma. In this study, we observed strongly gelsolin-positive pituitary gland. In this context, it is interesting to mention that in a reported case of pituicytoma, a very rare glioma of the pituitary gland of unknown cell origin, there were observed gelsolin amyloid deposits. However, there was not found any mutation in GSN (Ida et al. 2013).

More data about gelsolin in NC derivatives comes from studies concerning a very rare autosomal dominant disease: gelsolin amyloidosis known also as the familial amyloidosis of Finnish type (FAF). Single point mutation in GSN leads to generation of a protein, where in the position 187 instead of aspartic acid either asparagine or tyrosine residue is present. Interestingly, this substitution is amyloidogenic only in case of plasma gelsolin (isoform a). Only this isoform prior to secretion goes through endoplasmic reticulum and trans-Golgi network, where plasma gelsolin $^{\mathrm{D} 187 \mathrm{~N} / \mathrm{Y}}$ is cleaved by furin ( $\alpha$-gelsolinase). Next, truncated plasma gelsolin ${ }^{\mathrm{D} 187 \mathrm{~N} / \mathrm{Y}}$ is cleaved by metalloproteinases, e.g., MT1-MMP in extracellular space causing 


\section{A $\quad$ electroporation}

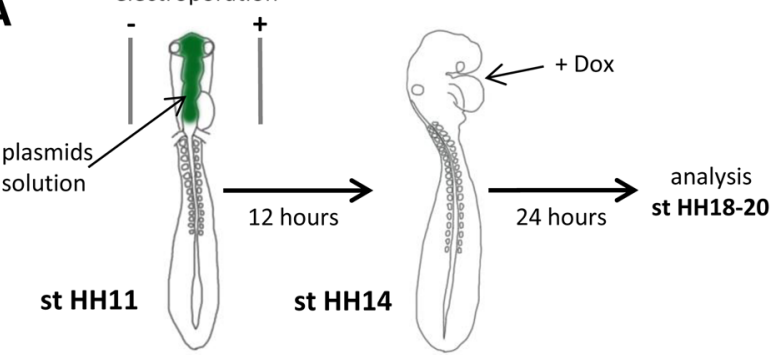

scRNAmirs GSN + Dox
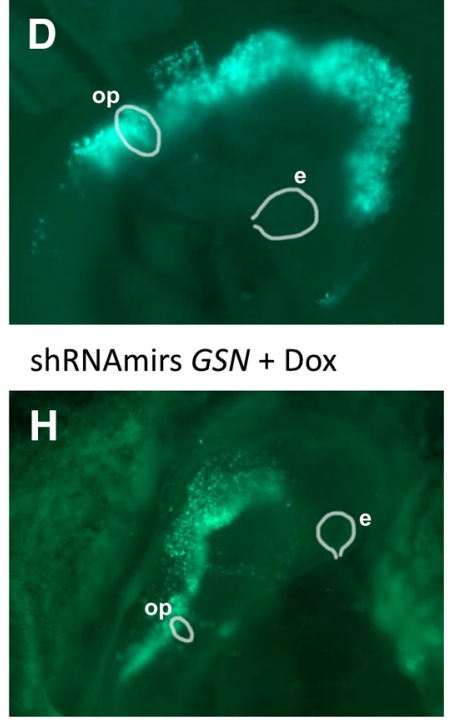

scRNAmirs GSN + Dox

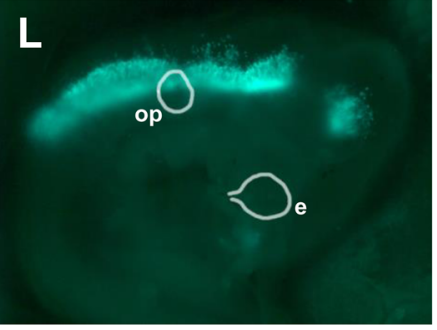

shRNAmirs GSN + Dox

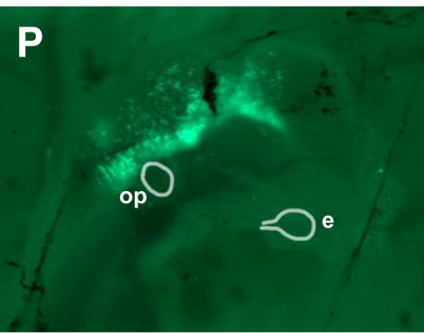

$\mathbf{T}$

\begin{tabular}{|l|l|}
\hline \multicolumn{1}{|c|}{ condition } & \multicolumn{1}{c|}{ observed effect } \\
\hline scRNAmirs GSN, GSN probe & 0 out of 5 embryos \\
\hline shRNAmirs GSN, GSN probe & 9 out of 12 embryos \\
\hline scRNAmirs GSN, CECR2 probe & 0 out of 4 embryos \\
\hline shRNAmirs GSN, CECR2 probe & 6 out of 8 embryos \\
\hline
\end{tabular}

shRNAmirs GSN - Dox

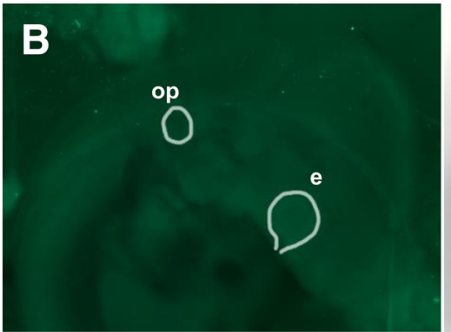

GSN probe

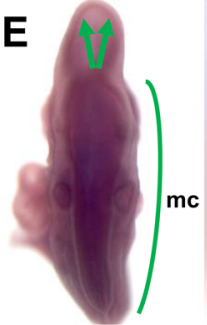

F

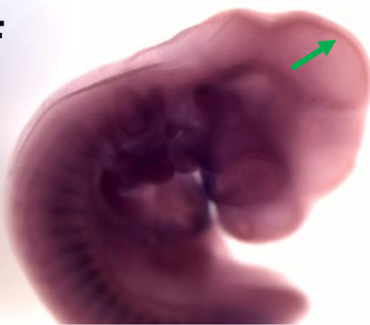

GSN probe

GSN probe

C
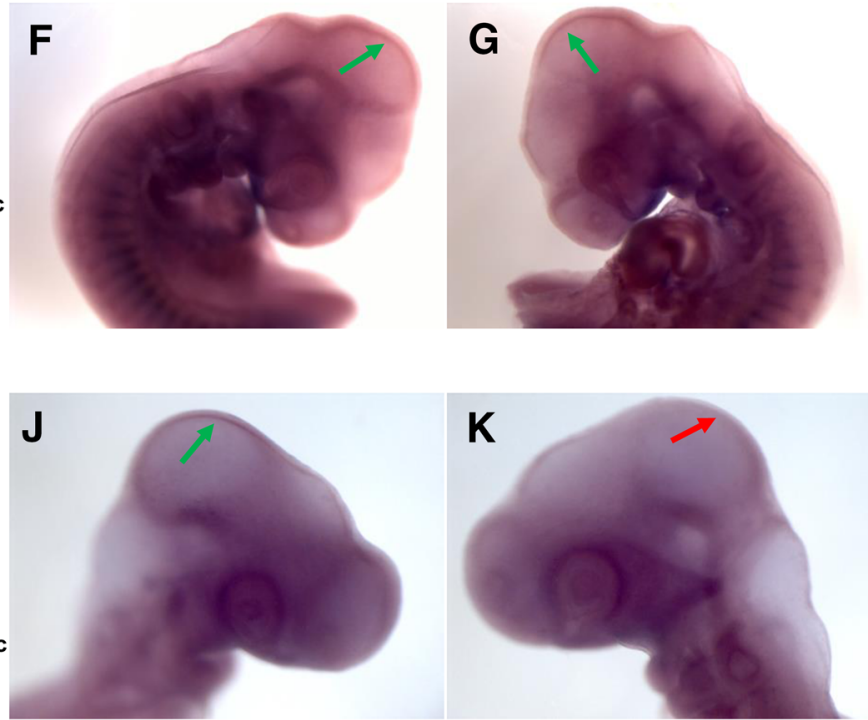

CECR2 probe

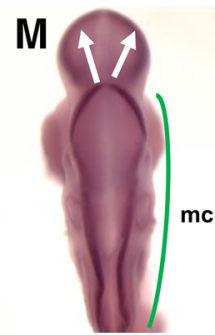

CECR2 probe
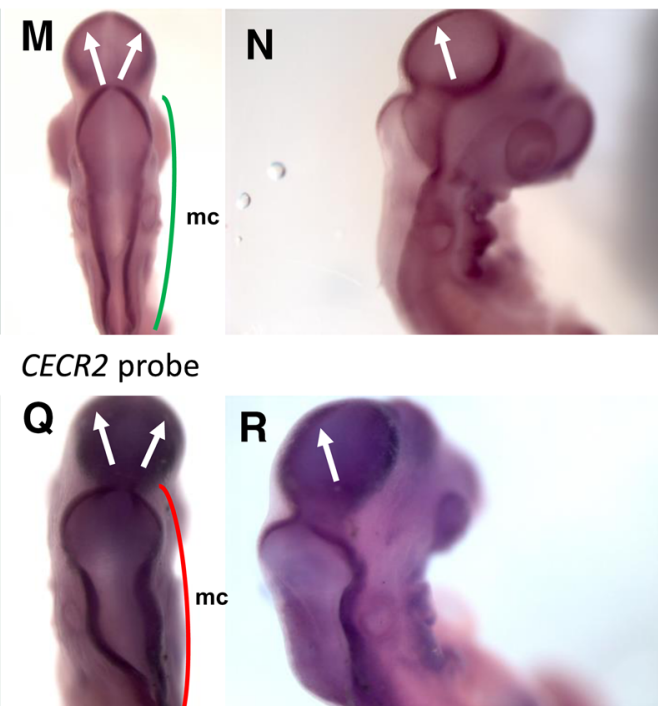

0

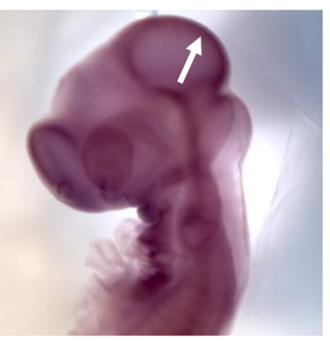

$\mathbf{R}$

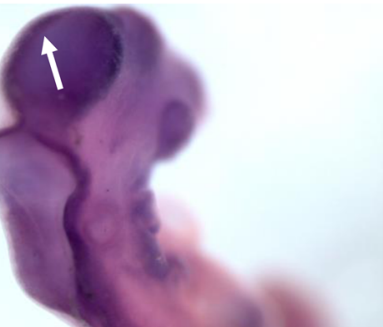

S

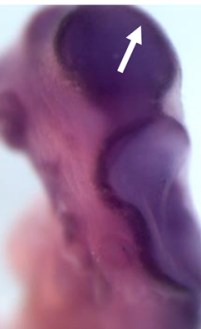


occurrence of amyloidogenic fragments. First manifestations of gelsolin amyloidosis are lattice dystrophy of the cornea and amyloid depositions found in eye elements: the sclera, the conjunctiva, nerves, and vessels. Next, cranial and peripheral nerves are affected, what leads to neuropathy. The skin is also affected by accumulation of amyloid deposits adjacent to basement membrane resulting in cutis laxa and in later phase of disease proteinuria and amyloid deposits in blood vessels occur (Solomon et al. 2012). Interestingly, in patients with FAF heart conduction abnormalities were observed such as atrio-ventricular block (Chastan et al. 2006) or arrhythmias (Stewart et al. 2000). Paunio (1998), applying in vitro techniques, showed that in contrast to earlier assumptions, not muscles, but cells of neural origin are most probably responsible for the secretion of truncated plasma gelsolin ${ }^{\mathrm{D} 187 \mathrm{~N} / \mathrm{Y}}$. Surprisingly, according to the authors, Schwann cells process only up to $7 \%$ of mutated form of plasma gelsolin, whereas cells of neuronal origin cleave $60-90 \%$ of plasma gelsolin ${ }^{\mathrm{D} 187 \mathrm{~N} / \mathrm{Y}}$ into amyloid fragments. However, keeping in mind FAF is manifested first in the third decade of life, it is plausible that low level of processing of mutated plasma gelsolin by Schwann cells could be possible. Nevertheless, it is also possible that other neural crest derivatives such as sensory neurons could also secrete plasma gelsolin ${ }^{\mathrm{D} 187 \mathrm{~N} / \mathrm{Y}}$, since patients with FAF had reduced sensation (Kiuru 1998). The character of gradually occurring symptoms of FAF supports our observations of enhanced GSN expression in some cell lineages of ectodermal origin and in all $\mathrm{NC}$ derivatives in the developing chicken.

\section{Future goals}

Although we observed enhanced GSN expression in NC derivatives, the biological significance of this phenomenon is unsolved and raises important questions. NC cells are highly motile and undergo EMT (Kuriyama and Mayor 2008). Together with the notion that gelsolin is a tumor suppressor, it suggests gelsolin's role in NC cells development can have other implications, than simply regulating the actin cytoskeleton and thus influencing cell motility. Another issue is that there were observed different gelsolin expression patterns in head muscles and skeletal muscles of, e.g., the neck. Western blot analysis performed by Kwiatkowski et al. (1988) revealed high GSN expression level in human and rat skeletal muscles. Thus, further studies are needed to identify gelsolin-positive cell types within skeletal muscles, especially in correlation to developmental stage and phase of life. Stunning is also the high GSN expression level in the splanchnopleure. Because gelsolin is indispensable for embryonic development in lower vertebrates playing most probably a signaling function (Kanungo et al. 2003) and gelsolin downregulation is of high importance during tumor transformation in humans ( $\mathrm{Li}$ et al. 2012), more effort should be put into the precise understanding of the role of gelsolin in development and cell motility. Among future goals there should also be the functional analysis of gelsolin in NC cells and in myelin producing cells in CNS and PNS. It should furthermore be elucidated by functional studies, if gelsolin is crucial for the chicken embryonic development like in zebrafish. Another issue to be elucidated is the estimation if GSN expression is correlated with Sox 10 involving pathways and if gelsolin is present in oligodendrocytes of the adult chicken brain. Moreover, it would be of considerable importance to check, if in chicken more than one gelsolin isoform is present. Identification of antibodies recognizing chicken gelsolin allows for more detailed analysis of gelsolin presence in organs from older chicken embryos, hatchlings, and adult animals, which could bring more valuable data for comparative studies and thus help to understand the role of gelsolin in NC derivatives and some cell lineages of ectodermal origin such as oligodendrocytes or cells becoming constituents of the optic and olfactory systems.

Acknowledgments The authors would like to thank Rana Houmany, Marion Otto, Ulrike Ritenberg, and Swantje Wulf for their excellent technical assistance. Special thanks are due to Ilona Styczeń for her important administrative contribution during this work. Antonina Mazur and Aleksandra Makowiecka wish specially to thank the Foundation for Polish Science for financial support of this study within the HOMING Plus Programme (HOMING Plus/2010-2/8) within the European Union Innovative Economy Programme.

Open Access This article is distributed under the terms of the Creative Commons Attribution License which permits any use, distribution, and reproduction in any medium, provided the original author(s) and the source are credited.

\section{References}

Adameyko I, Lallemend F, Aquino JB et al (2009) Schwann cell precursors from nerve innervation are a cellular origin of melanocytes in skin. Cell 139:366-379 .doi:10.1016/j.cell.2009. 07.049

Adameyko I, Lallemend F, Furlan A et al (2012) Sox2 and Mitf crossregulatory interactions consolidate progenitor and melanocyte lineages in the cranial neural crest. Development 139:397-410. doi:10.1242/dev.065581

Ambrosino C, Tarallo R, Bamundo A et al (2010) Identification of a hormone-regulated dynamic nuclear actin network associated with estrogen receptor alpha in human breast cancer cell nuclei. Mol Cell Proteomics 9:1352-1367. doi:10.1074/mcp.M900519MCP200

Bradford MM (1976) A rapid and sensitive method for the quantitation of microgram quantities of protein utilizing the principle of protein-dye binding. Anal Biochem 72:248-254

Bremer M, Fröb F, Kichko T et al (2011) Sox10 is required for Schwann-cell homeostasis and myelin maintenance in the adult peripheral nerve. Glia 59:1022-1032. doi:10.1002/glia.21173 
Chankiewitz V, Morosan-Puopolo G, Yusuf F et al (2014) A thymosin beta15-like peptide promotes intersegmental myotome extension in the chicken embryo. Histochem Cell Biol. doi:10. 1007/s00418-013-1156-Z

Chastan N, Baert-Desurmont S, Saugier-Veber P et al (2006) Cardiac conduction alterations in a French family with amyloidosis of the Finnish type with the p.Asp187Tyr mutation in the GSN gene. Muscle Nerve 33:113-119. doi:10.1002/mus.20448

Chen J, Morosan-Puopolo G, Dai F et al (2010) Molecular cloning of chicken Cecr2 and its expression during chicken embryo development. Int J Dev Biol 54:925-929. doi:10.1387/ijdb. 092933jc

Choe H, Burtnick LD, Mejillano $M$ et al (2002) The calcium Activation of gelsolin: insights from the $3 \AA$ structure of the G4G6/actin complex. J Mol Biol 324:691-702. doi:10.1016/S00222836(02)01131-2

Crowley MR, Head KL, Kwiatkowski DJ et al (2000) The mouse mammary gland requires the actin-binding protein gelsolin for proper ductal morphogenesis. Dev Biol 225:407-423. doi:10. 1006/dbio.2000.9844

Dai F, Yusuf F, Farjah GH, Brand-Saberi B (2005) RNAi-induced targeted silencing of developmental control genes during chicken embryogenesis. Dev Biol 285:80-90. doi:10.1016/j. ydbio.2005.06.005

Dathe V, Brand-Saberi B (2004) Expression of thymosin beta4 during chick development. Anat Embryol (Berl) 208:27-32. doi:10. 1007/s00429-003-0369-7

Deal KK, Cantrell VA, Chandler RL et al (2006) Distant regulatory elements in a Sox10-beta GEO BAC transgene are required for expression of Sox10 in the enteric nervous system and other neural crest-derived tissues. Dev Dyn 235:1413-1432. doi:10. 1002/dvdy.20769

Dittmer A, Dittmer J (2006) Beta-actin is not a reliable loading control in Western blot analysis. Electrophoresis 27:2844-2845. doi:10.1002/elps.200500785

Dupin E, Sommer L (2012) Neural crest progenitors and stem cells: from early development to adulthood. Dev Biol 366:83-95. doi:10.1016/j.ydbio.2012.02.035

Eaton SL, Roche SL, Llavero Hurtado M et al (2013) Total protein analysis as a reliable loading control for quantitative fluorescent Western blotting. PLoS ONE 8:e72457. doi:10.1371/journal. pone. 0072457

Gómez-Márquez J, Franco del Amo F, Carpintero P, Anadón R (1996) High levels of mouse thymosin beta4 mRNA in differentiating P19 embryonic cells and during development of cardiovascular tissues. Biochim Biophys Acta 1306:187-193

Gonçalves AF, Dias NG, Moransard M et al (2010) Gelsolin is required for macrophage recruitment during remyelination of the peripheral nervous system. Glia 58:706-715. doi:10.1002/glia. 20956

Gurniak CB, Perlas E, Witke W (2005) The actin depolymerizing factor $\mathrm{n}$-cofilin is essential for neural tube morphogenesis and neural crest cell migration. Dev Biol 278:231-241. doi:10.1016/ j.ydbio.2004.11.010

Hamburger V, Hamilton HL (1992) A series of normal stages in the development of the chick embryo. 1951. Dev Dyn 195:231-272. doi:10.1002/aja.1001950404

Hari L, Miescher I, Shakhova O et al (2012) Temporal control of neural crest lineage generation by $\mathrm{Wnt} / \beta$-catenin signaling. Development 139:2107-2117. doi:10.1242/dev.073064

Heller S, Sheane CA, Javed Z, Hudspeth AJ (1998) Molecular markers for cell types of the inner ear and candidate genes for hearing disorders. Proc Natl Acad Sci USA 95:11400-11405

Ida CM, Yan X, Jentoft ME et al (2013) Pituicytoma with gelsolin amyloid deposition. Endocr Pathol 24:149-155. doi:10.1007/ s12022-013-9254-y
Iguchi T, Yagi H, Wang C-C, Sato M (2012) A tightly controlled conditional knockdown system using the Tol2 transposonmediated technique. PLoS ONE 7:e33380. doi:10.1371/journal. pone. 0033380

Iwamoto K, Bundo M, Yamada K et al (2005) DNA methylation status of SOX10 correlates with its downregulation and oligodendrocyte dysfunction in schizophrenia. J Neurosci 25:5376-5381. doi:10.1523/JNEUROSCI.0766-05.2005

Kanungo J, Kozmik Z, Swamynathan SK, Piatigorsky J (2003) Gelsolin is a dorsalizing factor in zebrafish. Proc Natl Acad Sci USA 100:3287-3292. doi:10.1073/pnas.0634473100

Katoh K, Standley DM (2013) MAFFT multiple sequence alignment software version 7: improvements in performance and usability. Mol Biol Evol 30:772-780. doi:10.1093/molbev/mst010

Katoh K, Kuma K, Toh H, Miyata T (2005) MAFFT version 5: improvement in accuracy of multiple sequence alignment. Nucleic Acids Res 33:511-518. doi:10.1093/nar/gki198

Kawakami K (2007) Tol2: a versatile gene transfer vector in vertebrates. Genome Biol 8(Suppl 1):S7. doi:10.1186/gb-20078-s1-s7

Kawakami K, Shima A, Kawakami N (2000) Identification of a functional transposase of the Tol2 element, an Ac-like element from the Japanese medaka fish, and its transposition in the zebrafish germ lineage. Proc Natl Acad Sci USA 97:11403-11408. doi:10.1073/pnas.97.21.11403

Kiuru S (1998) Gelsolin-related familial amyloidosis, Finnish type (FAF), and its variants found worldwide. Amyloid 5:55-66

Koga A, Suzuki M, Inagaki H et al (1996) Transposable element in fish. Nature 383:30. doi:10.1038/383030a0

Kuriyama S, Mayor R (2008) Molecular analysis of neural crest migration. Philos Trans R Soc Lond B Biol Sci 363:1349-1362. doi:10.1098/rstb.2007.2252

Kwiatkowski DJ, Mehl R, Izumo S et al (1988) Muscle is the major source of plasma gelsolin. J Biol Chem 263:8239-8243

Laemmli UK (1970) Cleavage of structural proteins during the assembly of the head of bacteriophage T4. Nature 227:680-685. doi:10.1038/227680a0

Le Douarin NM, Creuzet S, Couly G, Dupin E (2004) Neural crest cell plasticity and its limits. Development 131:4637-4650. doi:10.1242/dev.01350

Levin MD, Lu MM, Petrenko NB et al (2009) Melanocyte-like cells in the heart and pulmonary veins contribute to atrial arrhythmia triggers. J Clin Invest 119:3420-3436. doi:10.1172/JCI39109

Li GH, Shi Y, Chen Y et al (2009) Gelsolin regulates cardiac remodeling after myocardial infarction through DNase I-mediated apoptosis. Circ Res 104:896-904. doi:10.1161/CIRCRE SAHA.108.172882

Li GH, Arora PD, Chen Y et al (2012) Multifunctional roles of gelsolin in health and diseases. Med Res Rev 32:999-1025. doi:10.1002/med.20231

Litwin M, Mazur AJ, Nowak D et al (2009) Gelsolin in human colon adenocarcinoma cells with different metastatic potential. Acta Biochim Pol 56:739-743

Litwin M, Nowak D, Mazur AJ et al (2012) Gelsolin affects the migratory ability of human colon adenocarcinoma and melanoma cells. Life Sci 90:851-861. doi:10.1016/j.lfs.2012.03.039

Ma M, Zhou L, Guo X et al (2009) Decreased cofilin1 expression is important for compaction during early mouse embryo development. Biochim Biophys Acta 1793:1804-1810. doi:10.1016/j. bbamcr.2009.09.009

Mannherz HG, Mazur AJ, Jockusch B (2010) Repolymerization of actin from actin:thymosin beta4 complex induced by diaphanous related formins and gelsolin. Ann N Y Acad Sci 1194:36-43. doi:10.1111/j.1749-6632.2010.05467.x

Mazur AJ, Gremm D, Dansranjavin T et al (2010) Modulation of actin filament dynamics by actin-binding proteins residing in 
lamellipodia. Eur J Cell Biol 89:402-413. doi:10.1016/j.ejcb. 2009.10.017

Milet C, Monsoro-Burq AH (2012) Neural crest induction at the neural plate border in vertebrates. Dev Biol 366:22-33. doi:10. 1016/j.ydbio.2012.01.013

Morosan-Puopolo G, Balakrishnan-Renuka A, Yusuf F et al (2014) Wnt11 is required for oriented migration of dermogenic progenitor cells from the dorsomedial lip of the avian dermomyotome. PLoS ONE 9:e92679. doi:10.1371/journal.pone. 0092679

Nag S, Ma Q, Wang $\mathrm{H}$ et al (2009) $\mathrm{Ca}^{2+}$ binding by domain 2 plays a critical role in the activation and stabilization of gelsolin. Proc Natl Acad Sci USA 106:13713-13718. doi:10.1073/pnas. 0812374106

Nag S, Larsson M, Robinson RC, Burtnick LD (2013) Gelsolin: the tail of a molecular gymnast. Cytoskeleton (Hoboken) 70:360-384. doi:10.1002/cm.21117

Nieto MA, Patel K, Wilkinson DG (1996) In situ hybridization analysis of chick embryos in whole mount and tissue sections. Methods Cell Biol 51:219-235

Nishimura K, Ting H-J, Harada Y et al (2003) Modulation of androgen receptor transactivation by gelsolin: a newly identified androgen receptor coregulator. Cancer Res 63:4888-4894

Ohnishi M, Matsumoto T, Nagashio R et al (2009) Proteomics of tumor-specific proteins in cerebrospinal fluid of patients with astrocytoma: usefulness of gelsolin protein. Pathol Int 59:797-803. doi:10.1111/j.1440-1827.2009.02447.x

Paunio T (1998) Cells of the neuronal lineage play a major role in the generation of amyloid precursor fragments in gelsolin-related amyloidosis. J Biol Chem 273:16319-16324. doi:10.1074/jbc. 273.26.16319

Perrin BJ, Ervasti JM (2010) The actin gene family: function follows isoform. Cytoskeleton (Hoboken) 67:630-634. doi:10.1002/cm. 20475

Sato Y, Kasai T, Nakagawa S et al (2007) Stable integration and conditional expression of electroporated transgenes in chicken embryos. Dev Biol 305:616-624. doi:10.1016/j.ydbio.2007.01. 043

Scaal M, Gros J, Lesbros C, Marcelle C (2004) In ovo electroporation of avian somites. Dev Dyn 229:643-650. doi:10.1002/dvdy. 10433

Schägger H (2006) Tricine-SDS-PAGE. Nat Protoc 1:16-22. doi:10. 1038/nprot.2006.4

Shakhova O, Zingg D, Schaefer SM et al (2012) Sox10 promotes the formation and maintenance of giant congenital naevi and melanoma. Nat Cell Biol 14:882-890. doi:10.1038/ncb2535
Shawlot W, Deng JM, Fohn LE, Behringer RR (1998) Restricted beta-galactosidase expression of a hygromycin-lacZ gene targeted to the beta-actin locus and embryonic lethality of betaactin mutant mice. Transgenic Res 7:95-103

Simon C, Lickert H, Götz M, Dimou L (2012) Sox10-iCreERT2: a mouse line to inducibly trace the neural crest and oligodendrocyte lineage. Genesis 50:506-515. doi:10.1002/dvg.22003

Solomon JP, Page LJ, Balch WE, Kelly JW (2012) Gelsolin amyloidosis: genetics, biochemistry, pathology and possible strategies for therapeutic intervention. Crit Rev Biochem Mol Biol 47:282-296. doi:10.3109/10409238.2012.661401

Stewart HS, Parveen R, Ridgway AE et al (2000) Late onset lattice corneal dystrophy with systemic familial amyloidosis, amyloidosis V, in an English family. Br J Ophthalmol 84:390-394

Swamynathan SK (2013) Ocular surface development and gene expression. J Ophthalmol 2013:103947. doi:10.1155/2013/ 103947

Tanaka J, Sobue K (1994) Localization and characterization of gelsolin in nervous tissues: gelsolin is specifically enriched in myelin-forming cells. J Neurosci 14:1038-1052

Tanaka H, Shirkoohi R, Nakagawa K et al (2006) siRNA gelsolin knockdown induces epithelial-mesenchymal transition with a cadherin switch in human mammary epithelial cells. Int J Cancer 118:1680-1691. doi:10.1002/ijc.21559

Towbin H, Staehelin T, Gordon J (1979) Electrophoretic transfer of proteins from polyacrylamide gels to nitrocellulose sheets: procedure and some applications. Proc Natl Acad Sci U S A 76:4350-4354

Vouyiouklis Da, Brophy PJ (1997) A novel gelsolin isoform expressed by oligodendrocytes in the central nervous system. J Neurochem 69:995-1005

Watanabe T, Saito D, Tanabe K et al (2007) Tet-on inducible system combined with in ovo electroporation dissects multiple roles of genes in somitogenesis of chicken embryos. Dev Biol 305:625-636. doi:10.1016/j.ydbio.2007.01.042

Winder SJ, Ayscough KR (2005) Actin-binding proteins. J Cell Sci 118:651-654. doi:10.1242/jcs.01670

Wirsching H-G, Kretz O, Morosan-Puopolo G et al (2012) Thymosin $\beta 4$ induces folding of the developing optic tectum in the chicken (Gallus domesticus). J Comp Neurol 520:1650-1662. doi:10. 1002/cne.23004

Witke W, Sharpe AH, Hartwig JH et al (1995) Hemostatic, inflammatory, and fibroblast responses are blunted in mice lacking gelsolin. Cell 81:41-51 